\title{
Imperfect Information and Saving in a Small Open Economy
}

Christian Daude and Agustin Roitman 


\title{
IMF Working Paper
}

Middle East and Central Asia Department (MCD)

\section{Imperfect Information and Saving in a Small Open Economy \\ Prepared by Christian Daude and Agustin Roitman ${ }^{1}$}

Authorized for distribution by Ralph Chami

March 2011

\begin{abstract}
This Working Paper should not be reported as representing the views of the IMF. The views expressed in this Working Paper are those of the author(s) and do not necessarily represent those of the IMF or IMF policy. Working Papers describe research in progress by the author(s) and are published to elicit comments and to further debate.

Emerging markets are more volatile and face different types of shocks, in size and nature, compared to their developed counterparts. Accurate identification of the stochastic properties of shocks is difficult. We show evidence suggesting that uncertainty about the underlying stochastic process is present in commodity prices. In addition, we build a dynamic stochastic general equilibrium model with informational frictions, which explicitly considers uncertainty about the nature of shocks. When formulating expectations, the economy assigns some probability to the shocks being temporary even if they are actually permanent. Parameter instability in the stochastic process implies that optimal saving levels (debt holdings) should be higher (lower) compared to a process with fixed parameters. Imperfect information about the nature of shocks matters when commodity GDP shares are high. Thus, economic policies based on misperception of the underlying regime can lead to substantial over/under saving with important associated costs.
\end{abstract}

JEL Classification Numbers: E21, F32, D82

Keywords: saving; commodity prices; uncertainty; Bayesian learning; Markov switching Authors E-Mail Addresses: christian.daude@oecd.org; aroitman@imf.org

\footnotetext{
${ }^{1}$ The authors would like to thank Pablo D'Erasmo, Anton Korinek, Anthony Lemus, Enrique Mendoza and Carmen Reinhart, as well as participants at the University of Maryland at College Park international and macro seminars, for helpful comments and suggestions. We are extremely grateful to Carlos Vegh for invaluable guidance. All remaining errors are exclusively our responsibility.
} 
Contents
Page

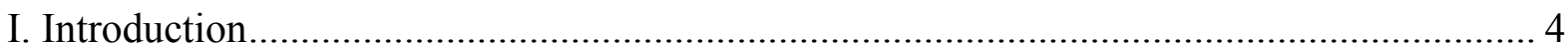

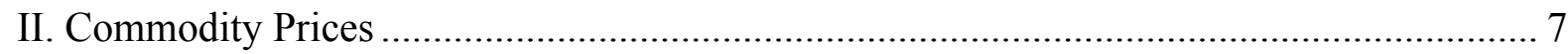

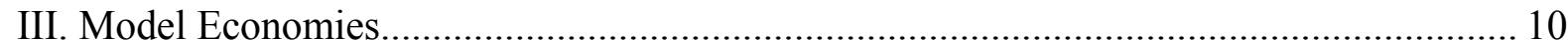

A. Stationary Model ................................................................................. 10

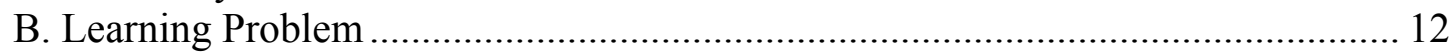

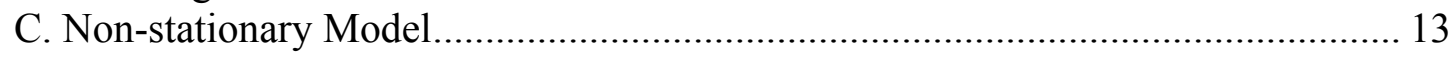

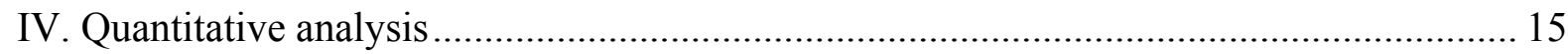

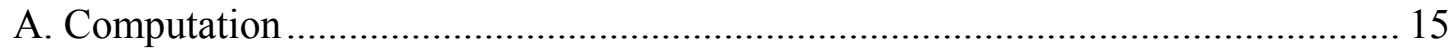

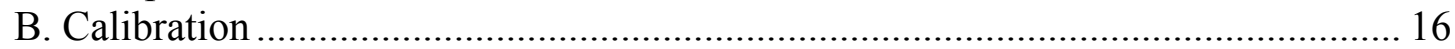

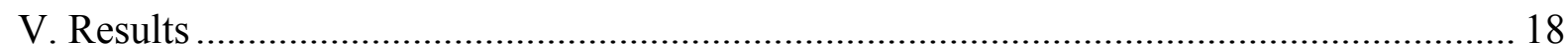

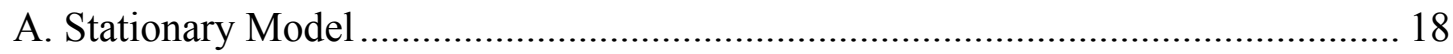

B. Stationary/Non-stationary Regime Switching Model ...................................... 20

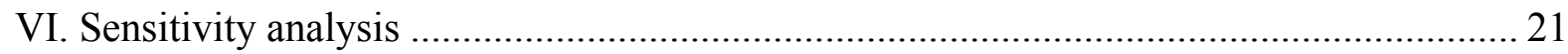

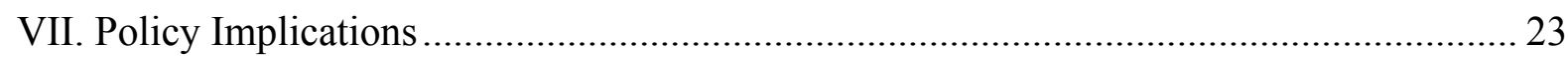

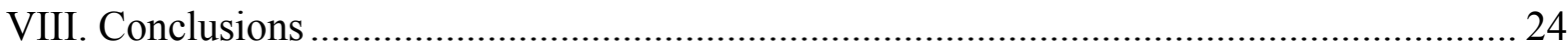

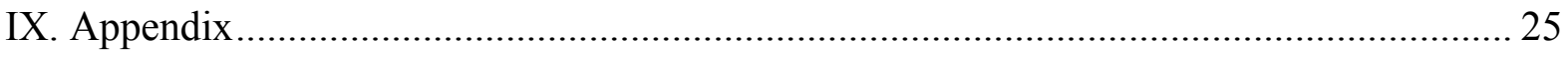

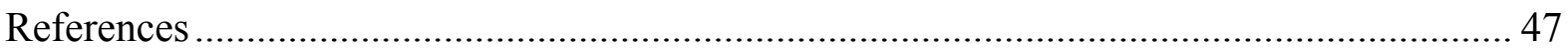

Tables

Table 1. Parameters for AR1 copper economy ............................................................... 16

Table 2. Parameters for AR1 Markov switching economy ............................................... 16

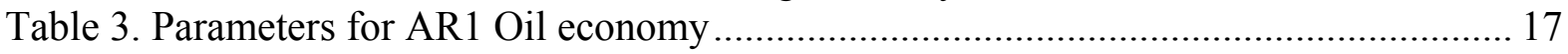

Table 4. Parameters for stationary/non-stationary Markov switching economy ................... 17

Table 5. Moments of the benchmark AR1 model with perfect information.......................... 18

Table 6. Moments of the AR1 model with perfect information and regime switching ......... 19

Table 7. Moments of the AR1 model with imperfect information and regime switching..... 19

Table 8. Moments of the benchmark model with perfect information for the oil economy ... 20

Table 9. Moments of the Markov switching model with perfect information for the oil

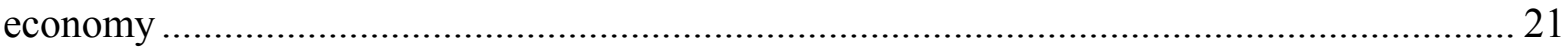

Table 10. Moments of the Markov switching model with imperfect information for the oil

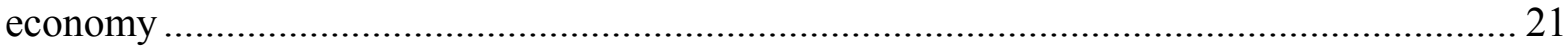

Table 11. Moments of the Markov switching model with higher share of commodity sector in

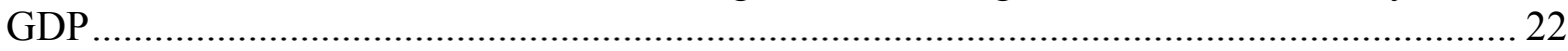

Table 12. Moments of the Markov switching model without learning $(\mathrm{mij}=0.5)$............... 22

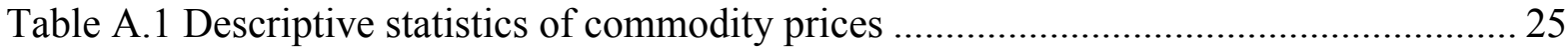

Table A.2 Variance Ratios ........................................................................................... 29

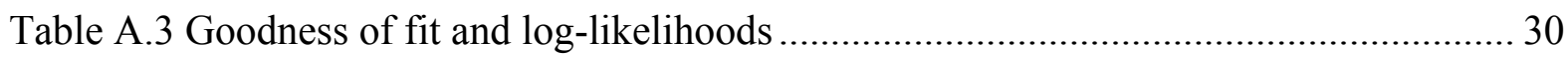


Figures

Figure A.1 Commodity Prices (constant US dollars) ..................................................... 31

Figure A.2.1 Rolling-window means (15-years) .......................................................... 35

Figure A.2.2 Rolling-window coefficients of variation (15-years).................................... 39

Figure A.2.3 Rolling-window autocorrelations (15-years) ......................................... 43 


\section{INTRODUCTION}

Macroeconomic theory and empirical evidence show that uncertainty has important effects on macroeconomic performance (i.e. economic growth, saving and investment). ${ }^{2}$ In particular, saving behaviour and current account balances in emerging markets are affected in very different ways depending on the type of shocks (i.e. temporary versus permanent). This phenomenon is particularly pervasive among commodity exporters, where high levels of volatility and uncertainty are common. ${ }^{3}$

However, most of the economic literature explaining saving behaviour in emerging markets has not focused on studying the relationship between uncertainty about the nature of shocks and optimal saving levels. Thus, a comprehensive understanding, a more realistic characterization of uncertainty, and its effects on economic performance and saving behaviour, are all still unexplored issues in the profession. The main contribution of our paper is to fill this gap in the literature by providing a standard small open economy model that explicitly allows for this type of uncertainty.

The behaviour of commodity prices constitutes also an econometric "puzzle" still unresolved. The empirical evidence presented below shows that "regime" changes (i.e., changes in parameters characterizing the underlying stochastic process such as persistence and/or volatility of innovations) in commodity prices are frequent and sizable. They are subject to large and unexpected fluctuations, and it is difficult to identify the statistical properties of the time-series (in particular, whether they are stationary or non-stationary processes). In this paper, we show some relevant features related to persistence of shocks and regime switches in these time series, using a sample of sixty two commodities over fifty years from IMF's International Financial Statistics.

Our model then builds on these facts and explores the optimal savings decisions in a small open economy where the representative agent is subject to uncertainty with respect to the regime in which commodity prices currently are (i.e., low persistence or high persistence regime). We assume that the agent knows the underlying law of motion between regimes and uses Bayesian learning to predict the state of the economy. Our main interest is to examine how optimal saving decisions are affected by this additional level of uncertainty.

Recent research shows that certain aspects of business cycles in developing countries are very different from business cycles in industrialized countries. ${ }^{4}$ In particular for commodity exporters, the persistence of shocks is very relevant because the implications in terms of the

\footnotetext{
${ }^{2}$ Ramey and Ramey (1995) find a significantly negative impact of volatility on economic growth. Mendoza (1997) provides an early contribution on the effects of terms of trade uncertainty on precautionary savings and economic growth. See also Aghion et al (2010) for a model put emphasis on the interaction between uncertainty and credit constraints and their effect on productivity enhancing investments.

${ }^{3}$ See Broda (2004), Kose (2002) and Mendoza (1995) on this issue.

${ }^{4}$ See Aguiar and Gopinath (2007).
} 
required economic adjustment (i.e. fiscal and external balances) and optimal saving levels are potentially very different. There are many countries in which the business cycle is mainly driven by fluctuations in commodity prices. Furthermore, this is also relevant from a fiscal point of view, given that fiscal revenues, royalties or direct income from state-owned enterprises are large in many developing countries. It is not accidental that Chile (the largest copper exporter in the world) has developed a structural balance rule that especially tries to identify transitory copper windfalls and save them for "rainy days". The present paper presents a framework to better understand these challenges from an analytical viewpoint.

One key element when studying optimal saving behaviour in emerging markets is to take into account the possibility of uncertainty about the type of shocks and regime changes (i.e., whether the economy is in a state of high or low persistence of shocks, and whether the economy is in a high or low volatility state). To be clear, we will refer to "the current regime" of commodity prices, as the one associated to a particular stochastic process, and to Markov switching between alternative regimes, as the process which allows switches in persistence and/or volatility of innovations. In terms of persistence of shocks, basic open macroeconomic principles (see e.g. Chapter 2 in Obstfeld and Rogoff, 1996) establish that a small open economy should finance temporary shocks and adjust to permanent shocks. However, these models in general are based on a perfect foresight environment where uncertainty does not play any relevant role in terms of optimal decision rules of economic agents. But uncertainty is definitely relevant due to its effect on optimal decisions and the importance of precautionary savings. Models with uncertainty have been used to study the consequences of considering alternative stochastic processes but always with complete information about their statistical properties and without considering neither variation in persistence nor volatility over time. The most commonly used process to introduce uncertainty in DSGE models is a first-order autoregressive process with a given persistence and a given variance for the innovations. This means that shocks are not only, always transitory, but also, that the variance of the innovations is exactly the same across time.

It is well understood that differences in the stochastic process characterising uncertainty can have different effects on the level of optimal savings as well as other macroeconomic variables and their cycles. The goal of this paper is to explore what are the consequences of explicitly considering that the current regime of the economy is uncertain and that it can change over time. In other words, we explicitly introduce uncertainty about whether the persistence of shocks is high or low and potentially also changes the level of uncertainty, at each point in time. To capture changes in persistence across time, we use a particular stochastic process in an otherwise standard small open economy model. We will study two alternative processes with different characteristics about their stationarity properties in order to assess how uncertainty about shocks being temporary or permanent affects optimal saving levels. In this way we introduce an additional layer of uncertainty which is precisely uncertainty not only about the particular realization of the shock (usual source of uncertainty), but also about the process (i.e., the nature of shocks).

Our framework constitutes a normative tool suitable to assess optimal saving behaviour in a realistic environment in which agents never know the "true" persistence of shocks. Following Reinhart and Wickham (1994): “...the key is how shocks are perceived by agents." In our model, agents use a learning technology which enables them to infer probabilities for the economy being in one regime or the other. To the best of our knowledge, this is the first study 
providing a simple theoretical framework to analyse how uncertainty about changes in persistence of shocks over time affect optimal saving levels. It has the advantage of being comparable with the standard DSGE model for a small open economy and constitutes a first step in the direction of understanding how this type of uncertainty affects saving levels and external balances of small open economies. In principle, taking into account this type of uncertainty is important for commodity exporters and seems to be the appropriate basic setup to think about optimal policy in the presence of realistic shock processes and informational frictions.

There is a vast empirical literature about commodity prices which has uncovered some stylized facts about their behaviour. Deaton and Laroque (1992) emphasise the existence of rare but large explosions in prices coupled with high degrees of persistence in more normal times. Grilli and Yang (1998) as well as Reinhart and Wickam (1994) argue that most commodity prices (in real terms) have a tendency to trend down in the long run. Leon and Soto (1995) claim that shocks to commodity prices exhibit relatively low persistence and there is room for stabilisation mechanisms (i.e. commodity stabilisation funds). On the other hand, Cashin et al (1999) present evidence supporting the existence of long lasting commodity price shocks and therefore argue that the costs of stabilisation funds might offset their benefits. Engel and Valdes (2001) conclude that there is no conclusive econometric evidence about processes with temporary or permanent shocks to better characterize copper prices. A good summary of these stylized facts can be found in Deaton (1999).

It has proven to be extremely difficult to characterize the long run as well as the short run behaviour of commodity prices. One of the reasons is that it is almost impossible that the persistence and volatility of the shocks be the same in 1930 and in 1995, no matter what commodity are we talking about. Another important reason is the fact that these prices exhibit large and unexpected swings even in the short run (Cashin et. al, 1999). Therefore, given that shocks cannot always be transitory or permanent a single data generating process (i.e., an AR1) would in principle be unable to provide a good characterization of the actual behaviour of commodity prices.

In terms of related theoretical studies, Deaton (1991) and Carroll (2008) provide theoretical foundations to appropriately write and define a particular type of dynamic stochastic problem in which, at least, one of the variables is not stationary. These studies focus on uncertainty and precautionary savings and provide the necessary tools to formulate and then solve a model with permanent shocks. Ghosh and Ostry (1994) develop a precautionary savings model to study export instability and the external balance in developing countries. They explore the implications of changes in the variance of export earning shocks and analyze how this type of uncertainty affects optimal saving levels and the external balance. Our model builds on this literature but considers an additional layer of uncertainty with respect to the type of stochastic process that drives commodity prices, allowing for changes over time in the persistence of shocks and their volatility.

Aguiar and Gopinath (2007) consider a model in which shocks "hitting" the economy have a trend and a cycle component. They match two business cycle facts of emerging markets that are difficult to match with the standard small open economy models (e.g. Mendoza, 1991) countercyclical trade balances and a higher volatility of consumption versus output. The authors argue that this is due to the prevalence of trend shocks. A related paper that incorporates learning about the trend and cycle components is Boz et al (2008). They show 
that once learning is included in the model, the prevalence of trend shocks is no longer needed. Van Nieuwerburgh and Veldkamp (2006) propose an explanation about how is the transition between booms and busts based on agents learning about productivity. They use a Bayesian filter to forecast the future realization of productivity. Boz (2009) also uses informational frictions as an explanation to emerging market crisis, and has the exact same device (learning about productivity) as van Nieuwerburgh and Veldkamp.

These papers have in common that the uncertainty is about decomposing total factor productivity shocks into permanent and transitory components. And the problem with their approach is that they focus on productivity shocks, about which there is some controversy in the profession. In contrast, uncertainty in our paper is about the underlying parameters, regimes or structure that is driving commodity prices. In this respect, our approach is more realistic, since commodity shocks are easier to observe. We allow autocorrelation coefficients of shocks and their variance to change over time rather than having a signal extraction problem regarding different realizations of shocks. This set-up is more relevant for commodity prices where - as we show in section II - regime switching between high and low volatility periods and changes in the persistence describe the statistical properties of the underlying stochastic process better than a "trend plus cycle" model with fixed parameters.

To study the effects of this type of uncertainty on saving behaviour in the simplest possible way, we will consider the standard DSGE small open economy model with a one-good endowment, adding two features. First, we will explicitly consider informational frictions. Second, we will consider two alternative stochastic processes, different from the standard AR1 commonly used in the literature. In particular, we study two alternative specifications to characterise and introduce uncertainty in the model. We first consider a stationary stochastic process (AR1 with regime switching) and then a non-stationary process.

The remainder of the paper is structured as follows. The next section presents empirical evidence on time varying persistence and volatility for sixty two commodity prices. In section III, we present the model economies. Section IV presents the quantitative analysis and the solution method. Section V discusses the main results. Section VI describes the policy implications. Finally, section VII concludes.

\section{COMmodity Prices}

This section presents the most salient features about commodity prices acknowledging that both permanent and transitory components are potentially present and may be time varying. We consider a sample of 58 annual commodity price time series ${ }^{5}$ over fifty years (1957-2007) from the IMF's International Financial Statistics. All original prices are in nominal US dollars, which we deflate by the US CPI. As standard unit root tests have very low power, whether commodity prices are better characterized by stationary or non-stationary processes is still an unresolved question which we do not directly address. Table A.1 in the appendix shows that the moments for commodity prices do vary significantly over time. This is a first indication of time variation in persistence and volatility in commodity prices.

\footnotetext{
5 The appendix presents the complete list.
} 
Following as similar approach as Reinhart and Wickham (1994), as we are also interested in looking at the behaviour of trends and variances for each commodity across time, we show that the permanent shocks are present (and fluctuate over time) in every commodity considered in our sample (Table A.2 and Figure A.1 in the appendix). Furthermore, decomposing the total volatility for the price of each commodity, into a permanent and a transitory component, we are able to disentangle their relative importance. Figure A.1 shows also that there is a distinct difference between soft commodities (like food and beverages) and non-reproducible industrial inputs, oil, or metals and ores. While the first tend to exhibit a downward trend, as Reinhart and Wickham (1994) also argue, the second group either does not exhibit a trend with most commodities presenting an upward trend in recent years. Regarding the behaviour of the variances of the series, we show that there are substantial changes (Figure A.2 in the appendix) across time in all commodity prices in our sample.

To study the permanent and cyclical components of commodity prices we decompose the series in two parts (trend and cycle) using the Hodrick-Prescott filter with a smoothing parameter equal to 100. Figure A.1 shows that despite the heterogeneity among different commodities, there is one common characteristic among all. Trends change a lot over time, and this feature is present in every commodity considered in our sample.

How much of the total volatility is due to the permanent component? To address this issue, we use Cochrane's (1988) methodology to quantify the importance of permanent shocks. Specifically, suppose the variable $p_{t}$ has the following representation:

$$
p_{t}=\alpha p_{t-1}+\varepsilon_{t} \text { with } \varepsilon_{t} \sim N\left(0, \sigma^{2}\right) \text {. }
$$

If $\alpha=1$ and the disturbance term is white noise, then $p_{t}$ follows a random walk and the variance of its k-differences grows linearly with the lag difference:

$$
\operatorname{var}\left(p_{t}-p_{t-k}\right)=k \sigma^{2}
$$

If $\alpha<1, p_{t}$ is a stationary process and the variance of its $\mathrm{k}$-differences is given by:

$$
\operatorname{var}\left(p_{t}-p_{t-k}\right)=\sigma^{2} \frac{1-\alpha^{2 k}}{1-\alpha^{2}}
$$

Therefore, the variance ratio $\frac{1}{k} \frac{\operatorname{var}\left(p_{t}-p_{t-k}\right)}{\operatorname{var}\left(p_{t}-p_{t-1}\right)}$ is equal to one if $p_{t}$ is a random walk. If $p_{t}$ is stationary, all shocks will eventually die out, hence the variance ratio will converge to zero. If $p_{t}$ is a general $I(1)$ process, which has both permanent and transitory (stationary) components, then the ratio will converge to the ratio of the variance of the permanent shock to the total variance of the process. Therefore, the closer that ratio is to unity, the larger is the size of the unit root component and the lower is the relative weight of the temporary shocks.

Table A.2 in the appendix presents the main results. The values of $k$ range between 1 and 20 years. There is substantial heterogeneity, but despite the different magnitudes, it is worth mentioning that the permanent component accounts for more than 30 percent of total volatility for thirteen commodities in the sample. Examples of this are coffee, iron ore, petroleum and 
tin, which seem to have substantial trend shocks over time. Despite the differences and relative importance of each component in each commodity, it is easy to see that permanent shocks are always present and can be a significant part of overall volatility in many cases.

To study the behaviour of the cyclical component, ${ }^{6}$ we explore if there is any evidence of "parameter instability" over time. We want to evaluate if there is any evidence of time variation in persistence and volatility of innovations coming from the cyclical component of commodity prices. It is not our aim to determine what factors are causing these switches nor to identify or link particular episodes or states to exogenous variables causing this behaviour. The objective here is to see if this regime switching happens for a wide variety of commodities, as the cyclical component of their prices appears to have different persistence and volatility of innovations over time.

We analyse the behaviour of the cyclical component of commodity prices over time estimating a Markov switching regime model a-la Hamilton (1989). For simplicity, we allow only two possible states for the parameters of the process. In particular, the two alternative models are the following. First, the Markov switching model is given by:

where $\varepsilon_{t} \sim N\left(0, \sigma_{t}^{2}\right)$.

$$
p_{t}=\mu_{t}+\rho_{t} p_{t-1}+\varepsilon_{t}
$$

Notice that in this model we allow the mean $\left(\mu_{t}\right)$, the persistence $\left(\rho_{t}\right)$, and the volatility of the innovations $\left(\sigma_{t}\right)$ to change over time. To keep it simple we will only allow two possible values for each parameter. So we estimated a 2-state Markov switching regime model. An alternative way to present this model is as follows:

$$
p_{t}=s_{t}\left[\mu^{A}+\rho^{A} p_{t-1}+\varepsilon_{t}^{A}\right]+\left(1-s_{t}\right)\left[\mu^{B}+\rho^{B} p_{t-1}+\varepsilon_{t}^{B}\right]
$$

where for some periods $s_{t}$ is an indicator function with a transition probability matrix given by:

$$
M=\left(\begin{array}{cc}
m_{11} & 1-m_{11} \\
1-m_{22} & m_{22}
\end{array}\right)=\left(\begin{array}{ll}
\operatorname{Pr}\left(s_{t+1}=1 \mid s_{t}=1\right) & \operatorname{Pr}\left(s_{t+1}=0 \mid s_{t}=1\right) \\
\operatorname{Pr}\left(s_{t+1}=1 \mid s_{t}=0\right) & \operatorname{Pr}\left(s_{t+1}=0 \mid s_{t}=0\right)
\end{array}\right)
$$

Thus, we estimate 8 parameters: $\mu^{A}, \mu^{B}, \rho^{A}, \rho^{B}, \sigma^{A}, \sigma^{B}, m_{11}$, and $m_{22}$.

Second, we estimate a standard AR(1) given by:

$$
p_{t}=\mu+\rho p_{t-1}+\varepsilon_{t}
$$

where $\varepsilon_{t} \sim N\left(0, \sigma^{2}\right)$, such that the mean, the persistence and volatility of innovations are fixed over time.

\footnotetext{
${ }^{6}$ A similar characterization results if we model price changes instead of the cyclical component.
} 
We select forty four commodities for which we have sufficiently long monthly observations (Table A.3 in the appendix) from the IMF's International Financial Statistics database to conduct our estimations. We use monthly data in order to have more observations. ${ }^{7}$ The time range considered is $1957 \mathrm{M} 1-2008 \mathrm{M} 12$. The cyclical component is obtained using the Hodrick-Prescott filter to de-trend the series, with a smooth parameter equal to 129,600 (following Ravn and Uhlig, 2002).

As shown in Table A.3, the results indicate that for twenty-eight of these commodities, the estimated Markov switching model is a good characterization of its cyclical behaviour. For the other commodities it is often the case that one or more coefficients (out of ten), were not statistically significant in the estimation, so we excluded them from the comparison. What is even more interesting is that for all these commodities the estimated model is undoubtedly superior (provides a better fit) than a standard AR1 model. The criterion to determine which of these two econometric models was better to characterise cyclical movements in commodity prices was to compare the log likelihood for each model and conduct the likelihood ratio test to check that these differences are statistically significant. Thus, the results of the estimation indicate that the regime switching approach seems to be a better characterisation compared to the widely used first order autoregressive model. It is important to emphasise that we are not claiming that this econometric model is the best among all possible models to characterize commodity prices. We just show that a model that allows regime switching in persistence and volatility seems to be more favoured by the data than the usual AR1 model. The intuition for this is that it allows more flexibility compared to other processes where persistence and volatility can only assume one particular constant value over time. Given our estimation results we conclude that there is evidence of time variation in persistence and volatility in the cyclical component of many commodity prices.

From this section, we conclude that there seems to be fluctuations in deep parameters of commodity price series over time. In particular, the evidence suggests the existence of sizable changes in both, persistence and volatility.

\section{MODEL ECONOMIES}

\section{A. Stationary Model}

We consider a simple dynamic stochastic general equilibrium (DSGE) model of a small open economy. There is one tradable good (i.e., commodity GDP) which can be sold in international markets at a given price. We consider a constant endowment of non-commodity GDP, for calibration purposes as explained below. The price of the tradable good is the only source of uncertainty in our model economy. The representative agent can borrow and lend in international capital markets at a time-invariant real interest rate. Markets are incomplete, such that the only financial instrument available is a one-period non-contingent bond that pays the world's real interest rate.

\footnotetext{
${ }^{7}$ Recall that for a two state Markov switching model in which we are allowing all the parameters to switch we are estimating 10 parameters.
} 
We start considering the simplest possible model where the price of the commodity follows a stationary AR(1) process and will use it as our benchmark. We then extend this model to incorporate two additional features.

First, the price is stochastic and is a combination of two stochastic processes, each of these, with different persistence and volatility. Second, we introduce informational frictions. To be precise, we will consider process uncertainty. The representative agent observes the actual realization of the commodity price, but she doesn't know the true properties (i.e., mean, persistence and standard deviation) of the process which generated it. Within every regime, we have the standard uncertainty of which particular shock hits the economy each period.

Suppose, to simplify, that there are only two states of the world (A and B). Each of these is characterized by a given distribution with well defined moments. ${ }^{8}$ We will first analyse how net foreign asset positions should be in this world, compared to the benchmark. Then we will add an extra layer of complication in order to analyze optimal debt levels under process uncertainty. Given this informational friction, the agent solves a learning problem. Using a Bayesian learning technology, she is updates beliefs and infers probabilities for the price coming from each of the possible distributions.

At the beginning of every period, the agent observes the realization of the price, updates her beliefs, and infers the corresponding probabilities for each possible distribution. Then, she chooses consumption and the level of net foreign assets she wants to hold.

The representative agent's preferences are given by:

$$
u\left(C_{t}\right)=\frac{C_{t}^{1-\theta}}{1-\theta},
$$

where $\theta$ is the coefficient of relative risk aversion. The agent maximizes the expected present discounted value of utility subject to the following resource constraint:

$$
C_{t}=P_{t} Y+A-B_{t+1}+R B_{t},
$$

where $C_{t}, Y$ and $B_{t}$ denote consumption, the commodity endowment and the net foreign asset position in period $t$, respectively; while $R=(1+r)$, where $r$ is the world real interest rate, which is assumed to be given and constant. The parameter $Y$ is the endowment of commodity goods available in the economy, while $A$ is the non-commodity GDP, which is also assumed to be constant. We introduce this parameter only for our quantitative analysis to calibrate the share of commodity GDP in total GDP.

For our benchmark model, the stochastic process for the commodity price is given by:

$$
P_{t}=P_{t-1}^{\rho} e^{\mu+\varepsilon_{t}},
$$

\footnotetext{
${ }^{8}$ One could think about this as periods of high volatility versus periods of low volatility. Another alternative is to think about periods of "persistent shocks" vs. periods of "less persistent shocks" (i.e., periods of permanent shocks vs periods of temporary shocks).
} 
where $\mu$ and $\rho$ are both constant over time, and the error terms $\left(\varepsilon_{t}\right)$ is assumed to be i.i.d. normal $N(0$, $\left.\sigma^{2}\right)$.

The first non standard feature that we will consider is "parameter instability" or time variation in persistence and volatility of the innovations. To this end we will consider the following stochastic process for the price:

$$
P_{t}=P_{t-1}^{\rho_{t}} e^{\mu_{t}+\varepsilon_{t}}
$$

where now $\mu_{t}$ and $\rho_{t}$ are both allowed to change over time, while $\varepsilon_{t}$ is assumed to be i.i.d. normal $N(0$, $\sigma_{t}^{2}$ ), such that the volatility of innovations is also allowed to change over time. To keep it simple we will only assume two possible stationary processes.

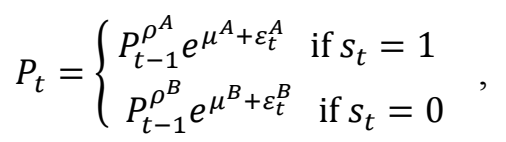

where both $\left|\rho^{A}\right|<1$ and $\left|\rho^{B}\right|<1, \varepsilon_{t}^{A} \sim N\left(0,\left(\sigma^{A}\right)^{2}\right)$ and $\varepsilon_{t}^{B} \sim N\left(0,\left(\sigma^{B}\right)^{2}\right)$ are both i.i.d., and $s_{t}$ is an unobserved "latent" variable which evolves according to an exogenous stationary Markov process.

\section{B. Learning Problem}

There are two "types" of uncertainty. First, there is process uncertainty. This means that shocks can be generated by distribution A or distribution B at each moment in time, and second, there is the usual uncertainty about the actual realization of the price.

The unobserved "latent" variable $s_{t}$ follows a two state Markov process with transition matrix given by:

$$
M=\left(\begin{array}{cc}
m_{11} & 1-m_{11} \\
1-m_{22} & m_{22}
\end{array}\right)
$$

which we assume is known by the agent. That is, $s_{t} \in\{0,1\}$ where $s_{t}=1$, corresponds to shocks coming from distribution $A$ and $s_{t}=0$ corresponds to shocks coming from distribution $B$. We also assume that the agent knows these distributions with certainty; she knows the mean, persistence and standard deviation of innovations of each possible distribution; what she cannot observe is $s_{t}$ and therefore whether the shock did actually came from $A$ or $B$. Following Boz (2007) we assume an irreducible Markov chain for the "latent" variable $s_{t}$, such that all elements are strictly positive and strictly smaller than 1.

At the beginning of each period the agent observes the actual price but do not observe past or present values of the latent variable. Therefore she uses the information revealed by the price to infer the probability of the shock in the current period coming from $A$ or $B$.

Beliefs are defined as:

$$
\tilde{s}_{t}=E\left[s_{t} \mid I_{t}^{U}\right]
$$

where $I_{t}^{U}$ is the information set which includes the entire history of realizations of the endowment observed by the agent, given by: 


$$
I_{t}^{U}=\left\{P_{t}, P_{t-1}, P_{t-2}, \ldots\right\}
$$

We will refer to this information structure as "imperfect information". The belief $\tilde{s}_{t}$ is formed by updating the previous period's belief $\tilde{s}_{t-1}$ using Bayes' rule:

$$
\operatorname{Pr}\left(s_{t-1}=s^{A} \mid I_{t}^{U}\right)=\frac{\operatorname{Pr}\left(P_{t}^{i} P_{t-1}^{j} \mid s^{A}\right) \operatorname{Pr}\left(s_{t-1}=s^{A} \mid I_{t}^{U}\right)}{\operatorname{Pr}\left(P_{t}^{i} P_{t-1}^{j} \mid s^{A}\right) \operatorname{Pr}\left(s_{t-1}=s^{A} \mid I_{t}^{U}\right)+\operatorname{Pr}\left(P_{t}^{i} P_{t-1}^{j} \mid s^{B}\right) \operatorname{Pr}\left(s_{t-1}=s^{B} \mid I_{t}^{U}\right)}
$$

The first probability in the numerator is the probability of observing the price at time $t$ given that the economy is in state $s^{A}$, while the second is the probability corresponding to $\tilde{s}_{t}$, given the one-to-one mapping between beliefs and probabilities in this set-up. Thus, we have:

$$
\left[\operatorname{Pr}\left(s_{t}=s^{A} \mid I_{t}^{U}\right) \quad \operatorname{Pr}\left(s_{t}=s^{A} \mid I_{t}^{U}\right)\right]=\left[\operatorname{Pr}\left(s_{t-1}=s^{A} \mid I_{t}^{U}\right) \quad \operatorname{Pr}\left(s_{t-1}=s^{A} \mid I_{t}^{U}\right)\right] M
$$

Consequently:

$$
\tilde{s}_{t}=\left[\operatorname{Pr}\left(s_{t}=s^{A} \mid I_{t}^{U}\right) \quad \operatorname{Pr}\left(s_{t}=s^{A} \mid I_{t}^{U}\right)\right]\left[\begin{array}{l}
s^{A} \\
s^{B}
\end{array}\right]
$$

We denote the evolution of the agent's beliefs as $\tilde{s}_{t+1}=\phi\left(\tilde{s}_{t}, P_{t+1}, P_{t}\right)$. When the agent makes her decisions at date $t, P_{t+1}$ is not known, but its distribution (conditional on $\tilde{s}_{t+1}$ ) is. It is in this way that she can form her expectations about shocks coming from one distribution or the other, using all the information available in period $t$.

\section{Non-stationary Model}

In this section we will study a more general process to characterise the evolution of the stochastic price over time. The main motivation behind this process is partly based on section II, and also based on the inconclusive evidence in the empirical literature about the stationarity or non-stationarity of commodity prices. Given these observations, we consider a stochastic process where stationarity can change over time. To be precise, the stochastic process for the price will be stationary during some periods of time and non-stationary during others.

$$
P_{t}=\left\{\begin{array}{ll}
P_{t-1}^{\rho} e^{\mu+\varepsilon_{t}^{A}} & \text { if } s_{t}=1 \\
P_{t-1} e^{\mu+\varepsilon_{t}^{B}} & \text { if } s_{t}=0
\end{array},\right.
$$

where $0<\rho<1$ and $\varepsilon_{t} \sim N\left(0, \sigma^{2}\right)$ is independently and identically normally distributed and $s_{t}$, is an unobserved "latent" variable which evolves according to an exogenous stationary Markov process, as before.

For simplicity, we will assume that both, the mean and the standard deviation of innovations is always the same regardless of whether the process for the price is stationary or nonstationary. This will enable us to focus only on the effects of time varying persistence on optimal saving levels. 
Since the overall process for the price is a combination of two processes, and given that one of these is non-stationary, the overall process is non-stationary. In order to be able to solve the model, we need to normalize all variables to induce stationarity.

Let $\hat{C}_{t}=\alpha_{t} C_{t}, \hat{Y}_{t}=\alpha_{t} Y_{t}, \hat{B}_{t}=\alpha_{t} B_{t}$, with $\alpha_{t}=\frac{1}{P_{t-1}}$. Therefore, after de-trending, the resource constraint becomes:

$$
\hat{C}_{t}=\hat{P}_{t}\left(Y-\hat{B}_{t+1}\right)+R \hat{B}_{t}+\hat{A}_{t}
$$

where $\hat{P}_{t}$ is given by:

$$
\hat{P}_{t}=\left\{\begin{array}{cc}
P_{t-1}^{\rho-1} e^{\mu+\varepsilon_{t}} & \text { if } s_{t}=1 \\
e^{\mu+\varepsilon_{t}} & \text { if } s_{t}=0
\end{array}\right.
$$

Now, the sequential problem for the agent is:

$$
\max _{\left\{\hat{C}_{t}, \hat{B}_{t+1}\right\}_{t=0}^{\infty}} E_{0}^{P}\left[E_{0}\left[\sum_{t=0}^{\infty} \beta^{t}\left(P_{t-1}^{1-\theta}\right) \frac{\hat{C}_{t}^{1-s}}{1-s} \mid I_{0}^{U}\right]\right],
$$

subject to equation (11). $E_{0}^{P}$ is the expectations operator with respect to the process/regime, while $E_{0}$ is the expectations operator with respect to the particular realisation of the endowment. The first order conditions for the competitive equilibrium are:

$$
\begin{gathered}
\beta^{t}\left(P_{t-1}^{1-\theta}\right) u^{\prime}\left(\hat{C}_{t}\right)-\lambda_{t}=0, \\
-\lambda_{t} \hat{P}_{t}+E_{t}^{P}\left\{E_{t}\left[\lambda_{t+1} R \mid I_{0}^{U}\right]\right\}=0,
\end{gathered}
$$

which combined yield the Euler equation:

$$
u^{\prime}\left(\hat{C}_{t}\right)=R \beta\left(P_{t}^{1-\theta}\right) E_{t}^{p}\left\{E_{t}\left[u^{\prime}\left(\hat{C}_{t+1}\right) \mid I_{0}^{U}\right]\right\},
$$

which has the usual interpretation. The marginal benefit of saving an additional unit of the endowment is equal to the marginal cost of not consuming that unit. The expectation on the right-hand side can be written as:

$\operatorname{Pr}\left(s_{t+1}=0 \mid I_{t}^{U}\right) E_{t}^{A R}\left[u^{\prime}\left(\hat{C}_{t+1}\right) \mid I_{0}^{U}\right]+\operatorname{Pr}\left(s_{t+1}=1 \mid I_{t}^{U}\right) E_{t}^{U R}\left[u^{\prime}\left(\hat{C}_{t+1}\right) \mid I_{0}^{U}\right]$,

such that it is a weighted average of the expectations under transitory shocks(AR1) and permanent shocks (UR process).

Definition: A competitive equilibrium is given by allocations $\hat{B}_{t+1}=b\left(\hat{B}_{t}, \hat{P}_{t}, \tilde{s}_{t}\right), \hat{C}_{t+1}=$ $c\left(\hat{B}_{t}, \hat{P}_{t}, \tilde{s}_{t}\right)$, such that:

(i) Agents maximise expected utility (13) subject to their budget constraint (11).

(ii) Goods and assets markets clear. 


\section{QuanTITATIVE ANALYSIS}

\section{A. Computation}

\section{Stationary case}

The recursive representation of the agent's problem is:

$$
V(B, P, \tilde{s})=\max \left\{u(C)+\beta E\left[V\left(B^{\prime}, P^{\prime}, \tilde{s}^{\prime}\right) \mid P, \tilde{s}\right]\right\}
$$

subject to:

$$
C=P Y+A-B^{\prime}+R B
$$

The solution algorithm includes the following steps:

1. Discretise the state space. We use 200 equally spaced nodes for $B, 5$ grid points for the price and 20 equally spaced nodes for $\tilde{s}_{t}$.

2. Evaluate the evolution of beliefs $\tilde{s}_{t+1}=\phi\left(\tilde{s}_{t}, P_{t+1}, P_{t}\right)$ using equations (7) - (9).

3. Solve the dynamic programming problem described in (14) using value function iterations in order to get $B_{t+1}=b\left(B_{t}, P_{t}, \tilde{s}_{t}\right), C_{t+1}=c\left(B_{t}, P, \tilde{s}_{t}\right)$.

\section{Non-stationary case}

The recursive representation of the agent's problem is:

$V(\widehat{B}, \hat{P}, \tilde{s})=\max \left\{u(\hat{C})+\beta(\widehat{P})^{1-\theta}\left[p^{S}(\widehat{P}, \tilde{s}) \int V\left(\widehat{B}^{\prime}, \widehat{P}^{\prime}, \tilde{s}\right) d F\left(\widehat{P}^{\prime} \mid \widehat{P}\right)+p^{N S}(\widehat{P}, \tilde{s}) \int V\left(\widehat{B}^{\prime}, \widehat{P}^{\prime}, \tilde{s}^{\prime}\right) d G\left(\widehat{P} \widehat{P}^{\prime} \mid \widehat{P}\right)\right]\right\}$, subject to

$$
\hat{C}=\hat{P}\left(Y-\widehat{B}^{\prime}\right)+R \widehat{B}+\hat{A}
$$

where $F($.) and $G($.) are the stationary and non-stationary distributions for the endowment respectively, $p^{S}$ and $p^{N S}$ are the conditional probabilities for the distribution being stationary and non-stationary respectively.

The solution algorithm includes the following steps:

1. Discretise the state space. We use 200 equally spaced nodes for assets, 5 grid points for the commodity price, and 20 equally spaced nodes for the latent state variable. To discretise the stationary and non-stationary stochastic processes we use Tauchen's (1986) method.

2. Evaluate the evolution of beliefs $\tilde{s}_{t+1}=\phi\left(\tilde{s}_{t}, P_{t+1}, P_{t}\right)$ using equations (7) - (9).

3. Solve the dynamic programming problem described in (15) using value function iterations in order to get $\hat{B}_{t+1}=b\left(\hat{B}_{t}, \hat{P}_{t}, \tilde{s}_{t}\right), \hat{C}_{t+1}=c\left(\widehat{B}_{t}, \hat{P}_{t}, \tilde{s}_{t}\right)$. 


\section{B. Calibration}

For the stationary model, we will use data for copper prices and the Chilean economy. For preferences and the risk free interest rate we use standard parameters in the literature. The stochastic process (AR(1) in this case) is estimated using data from the IMF International Financial Statistics (IFS). Since we divide total GDP in commodity GDP and non-commodity GDP, we will use a parameter $A$ to calibrate the share of copper GDP in total GDP. On average, between 1993 and 2009, copper has accounted for around 7 percent of total GDP. The resulting parameters are presented in Table 1.

Table 1. Parameters for AR1 copper economy

\begin{tabular}{cc}
\hline Parameter & Parameter value \\
\hline$\beta$ & 0.98 \\
$\theta$ & 2 \\
$r$ & 0.017 \\
$\sigma$ & 0.063 \\
$\rho$ & 0.91 \\
$\mu$ & 0.001 \\
$Y$ & 1 \\
$A$ & 12 \\
\hline
\end{tabular}

Table 2 shows the parameters for the stationary model with time varying parameters. These correspond to our estimation results of a regime switching AR(1) model. For simplicity, we allow the mean, the persistence and the volatility of innovations to take two possible values over time. The share of copper GDP in total GDP continues to be 7 percent, in order to make it comparable to the benchmark.

Table 2. Parameters for AR1 Markov switching economy

\begin{tabular}{cc}
\hline Parameter & Parameter value \\
\hline$\beta$ & 0.98 \\
$\theta$ & 2 \\
$r$ & 0.017 \\
$\rho^{A}$ & 0.9316 \\
$\rho^{B}$ & 0.8877 \\
$\sigma^{A}$ & 0.0359 \\
$\sigma^{B}$ & 0.0925 \\
$\mu^{A}$ & -0.0034 \\
$\mu^{B}$ & 0.0091 \\
$Y$ & 1 \\
$A$ & 12 \\
$m_{11}$ & 0.94 \\
$m_{22}$ & 0.90 \\
\hline
\end{tabular}

For the discount rate, the risk free interest rate and the coefficient of relative risk aversion, we use standard values used in the literature.

For the switching model between a stationary and non-stationary model we calibrate both the benchmark and the more general model to Mexico and oil prices. For the Benchmark model we use the parameter A to match the share of oil GDP in total GDP, which is also around 7 
percent for the Mexican economy. We choose the persistence and volatility of innovations for the price process in order to match the actual volatility and persistence of petroleum prices. Table 3 shows the resulting parameters for the AR1 benchmark model.

Table 3. Parameters for AR1 oil economy

\begin{tabular}{cc}
\hline Parameter & Parameter value \\
\hline$\beta$ & 0.98 \\
$\theta$ & 2 \\
$r$ & 0.017 \\
$\sigma$ & 0.14 \\
$\rho$ & 0.78 \\
$\mu$ & 0 \\
$Y$ & 1 \\
$A$ & 12 \\
\hline
\end{tabular}

For the non-stationary model with permanent and transitory shocks, the non-stationary part has a unit root by construction. We choose the persistence and the volatility of innovations of the stationary part, as well as the transition matrix (between the stationary and non-stationary parts) to match the actual persistence and volatility in petroleum prices. For simplicity, and also to isolate the effect of persistence, we assume that the volatility of innovations of the stationary part and the non-stationary parts are exactly the same. The share of petroleum GDP in total GDP continues to be 7 percent. The parameters are shown in Table 4.

Table 4. Parameters for stationary/non-stationary Markov switching economy

\begin{tabular}{cc}
\hline Parameter & Parameter value \\
\hline$\beta$ & 0.98 \\
$\theta$ & 2 \\
$r$ & 0.017 \\
$\rho^{A R I}$ & 0.687 \\
$\rho^{U R}$ & 1 \\
$\sigma$ & 0.18 \\
$\mu$ & 0 \\
$Y$ & 1 \\
$A$ & 12 \\
$m_{11}$ & 0.97 \\
$m_{22}$ & 0.80 \\
\hline
\end{tabular}




\section{REsults}

In this section we present and explain the main results obtained for each of the two models described above. Our main interest is to study how "parameter instability" affects optimal saving levels. The non-stationary model can be viewed as a case in which the economy faces both permanent and transitory shocks and our interest is to assess how the presence of this alternating stochastic process between temporary and permanent shocks affects optimal average assets holdings.

\section{A. Stationary Model}

In Table 5, we present the moments for the AR1 model with perfect information. In this case, all the results of the standard small open economy textbook model hold. First, consumption volatility is smaller than total output volatility. Second, there is a positive correlation between total output and consumption. Third, the correlation between assets holdings and output is positive. This means that in "good times" the economy is saving and in "bad times" it is dissaving, due to the consumption smoothing motive. Fourth, the correlation between output and the current account (CA) is positive. And fifth, on average, the CA is zero, which means that debts are always repaid. Notice also that total output is uncertain, and consumers are prudent (Kimball, 1990), therefore they have a precautionary motive to save. This basically implies saving for a rainy day. It is important to highlight the fact that there are two main motives to save. First, the consumption smoothing motive because consumers are risk averse and want to smooth consumption over time. Second, there is a precautionary savings motive because consumers are prudent. ${ }^{9}$

Table 5. Moments of the benchmark AR1 model with perfect information

\begin{tabular}{llllll}
\hline Moments & $\boldsymbol{P Y}$ & $\boldsymbol{B}$ & $\boldsymbol{C}$ & $\boldsymbol{T B}$ & $\boldsymbol{C A}$ \\
\hline Mean & 0.070 & -0.4719 & 0.9918 & 0.0082 & 0 \\
Std Deviation & 0.1288 & 0.2372 & 0.0088 & 0.0445 & 0.0438 \\
Autocorrelation & 0.8404 & 0.9622 & 0.872 & 0.692 & 0.6892 \\
\hline & $\operatorname{corr}(B, Y)$ & $\operatorname{corr}(C, Y)$ & $\operatorname{corr}(B, C)$ & $\operatorname{corr}(T B, Y)$ & $\operatorname{corr}(C A, Y)$ \\
\hline Correlation & 0.4784 & 0.9448 & 0.4842 & 0.5245 & 0.4802 \\
\hline
\end{tabular}

Let us consider now the model with parameter instability, meaning that the mean, the persistence and the volatility of innovations are time varying, with the parameters of Table 2 . Table 6 shows the corresponding moments for the case where the agents have perfect information with respect to the regime in which the economy currently is.

\footnotetext{
${ }^{9}$ It is worth mentioning that consumers may very well be risk averse but imprudent (see Roitman, 2010).
} 
Table 6. Moments of the AR1 model with perfect information and regime switching

\begin{tabular}{llllll}
\hline Moments & $\boldsymbol{P Y}$ & $\boldsymbol{B}$ & $\boldsymbol{C}$ & $\boldsymbol{T B}$ & $\boldsymbol{C A}$ \\
\hline Mean & 0.070 & -0.2931 & 0.9953 & 0.0047 & -0.001 \\
Std Deviation & 0.1877 & 1.4427 & 0.0143 & 0.2852 & 0.2813 \\
Autocorrelation & 0.7605 & 0.9736 & 0.7499 & 0.6941 & 0.6915 \\
\hline & $\operatorname{corr}(B, Y)$ & $\operatorname{corr}(C, Y)$ & $\operatorname{corr}(B, C)$ & $\operatorname{corr}(T B, Y)$ & $\operatorname{corr}(C A, Y)$ \\
\hline Correlation & 0.3713 & -0.0974 & 0.514 & 0.7569 & 0.6089 \\
\hline
\end{tabular}

Table 7. Moments of the AR1 model with imperfect information and regime switching

\begin{tabular}{llllll}
\hline Moments & $\boldsymbol{P} \boldsymbol{B}$ & $\boldsymbol{B}$ & $\boldsymbol{C}$ & $\boldsymbol{T B}$ & $\boldsymbol{C A}$ \\
\hline Mean & 0.070 & -0.4483 & 0.9924 & 0.0076 & -0.0002 \\
Std Deviation & 0.1877 & 0.3941 & 0.0114 & 0.0808 & 0.0798 \\
Autocorrelation & 0.7605 & 0.9593 & 0.8071 & 0.6717 & 0.6689 \\
\hline & $\operatorname{corr}(B, Y)$ & $\operatorname{corr}(C, Y)$ & $\operatorname{corr}(B, C)$ & $\operatorname{corr}(T B, Y)$ & $\operatorname{corr}(C A, Y)$ \\
\hline Correlation & 0.4103 & 0.93 & 0.4203 & 0.6926 & 0.5589 \\
\hline
\end{tabular}

The first and most important difference with the benchmark is that in this case, average assets holdings are higher (i.e., debt is lower). The economy is holding one third of the debt in comparison to the benchmark case. Intuitively, in this world, the representative agent knows that the price follows a stochastic process with parameter instability. This implies that there can be big jumps when there is a change in persistence or volatility. Furthermore, there is uncertainty about when a particular jump is going to take place. The agent knows this and since he is interested in having a smooth consumption path, the optimal thing to do is to accumulate a buffer stock of assets that enables her to save in order to prevent big fluctuations in the optimal consumption path. The rest of the results are qualitatively the same.

Consumption volatility is lower than total output volatility. Assets holdings go up in good times and down in bad times, consumption is positively correlated with total output and the current account is pro-cyclical.

Going one step further, we are interested in the effects of process uncertainty on optimal saving levels. Table 7 presents the moments for the case where parameters are the same as those for Table 6 (i.e. parameters correspond to Table 2), but there is process/regime uncertainty, such that the agent does not know the true state of the economy. Notice that in this case the level of average assets holdings is more than one and a half times lower than in the case of perfect information. While the debt/GDP ratio under perfect information is 29.3 percent, it is 44.8 percent under imperfect information. At the same time, net foreign assets are higher compared to the benchmark (i.e., the debt/GDP levels is about 6 percentage points lower).

Let us first analyze why under imperfect information the optimal debt level is higher compared to the case of perfect information. When the agent can only observe the shock but does not know from which distribution it is coming from, she needs to form beliefs (with the corresponding associated probabilities) in order to infer the distribution which generated the observed realization of the price. These beliefs (and probabilities) are used to form expectations which are in turn used to decide the amount of net foreign assets to hold. Intuitively, one could identify two effects. On the one hand, the fact of not knowing for sure 
where the observed realization is coming from (and because of the way beliefs are formed) makes the agent behave as if it were coming from the average between the two possible distributions. It is as if the economy were facing a process characterized by the average mean, persistence and volatility of innovations. On the other hand, there is an additional effect which would in principle induce agents to save more, and this is the process uncertainty effect. It turns out that the effect of the former is bigger than the latter.

The rest of the moments are qualitatively similar as under perfect information and the benchmark.

\section{B. Stationary/Non-stationary Regime Switching Model}

For the case where the commodity price can alter between a stationary and a non-stationary regime, the exercise will be to establish a benchmark - in this case for the case of oil in the Mexican economy - and then look at the effects of considering a more general process, with particular focus on average assets holdings levels. The resulting moments are presented in Table 8. For this benchmark model the results are qualitatively the same as for the case of Chile. Notice however that a key assumption here is that oil prices are stationary (i.e., they are characterized by a first order autoregressive process).

Table 8. Moments of the benchmark model with perfect information for the oil economy

\begin{tabular}{llllll}
\hline Moments & $\boldsymbol{P Y}$ & $\boldsymbol{B}$ & $\boldsymbol{C}$ & $\boldsymbol{T B}$ & $\boldsymbol{C A}$ \\
\hline Mean & 0.070 & -0.445 & 0.9925 & 0.0075 & -0.0002 \\
Std Deviation & 0.200 & 0.1945 & 0.0067 & 0.1212 & 0.12 \\
Autocorrelation & 0.380 & 0.8014 & 0.4508 & 0.3835 & 0.3829 \\
\hline & $\operatorname{corr}(B, Y)$ & $\operatorname{corr}(C, Y)$ & $\operatorname{corr}(B, C)$ & $\operatorname{corr}(T B, Y)$ & $\operatorname{corr}(C A, Y)$ \\
\hline Correlation & 0.408 & 0.8262 & 0.1311 & 0.9071 & 0.4116 \\
\hline
\end{tabular}

Consider now the model in which the process is allowed to be, some periods stationary and some periods non stationary. We can see three striking differences with the benchmark. First, average assets holdings are substantially higher. While under the AR1 assumption the stationary debt-to-GDP ratio is 44.5 percent, under the regime switching model, where the oil price can alter between a stationary and non-stationary regime, average debt-to-GDP is just 5.2 percent, as shown in Table 9. Second, the difference between consumption and total output volatility are substantially smaller compared to the benchmark. This is not that surprising, given that the correlation between consumption and output is almost 1 . Third, the current account is countercyclical. The agent knows that the changes in persistence could have dramatic consequences because in one of the regimes the process is non-stationary. The best forecast as of today that the agent can have, conditional on shocks coming from that process, is today's realization. This induces the agent to save considerably more than in the case in which he always faces temporary shocks. 
Table 9. Moments of the Markov switching model with perfect information for the oil economy

\begin{tabular}{llllll}
\hline Moments & $\boldsymbol{P Y}$ & $\boldsymbol{B}$ & $\boldsymbol{C}$ & $\boldsymbol{T B}$ & $\boldsymbol{C A}$ \\
\hline Mean & 0.070 & -0.0526 & 1.0029 & -0.0029 & -0.0038 \\
Std Deviation & 0.200 & 6.5759 & 0.169 & 9.1458 & 8.8968 \\
Autocorrelation & 0.380 & -0.0091 & 0.5581 & -0.4454 & -0.4429 \\
\hline & $\operatorname{corr}(B, Y)$ & $\operatorname{corr}(C, Y)$ & $\operatorname{corr}(B, C)$ & $\operatorname{corr}(T B, Y)$ & $\operatorname{corr}(C A, Y)$ \\
\hline Correlation & -0.6604 & 0.9901 & -0.6153 & 0.4735 & -0.2599 \\
\hline
\end{tabular}

As before, we are also interested in assessing the effects of process uncertainty on optimal saving levels, now under permanent and transitory shocks. The results are presented in Table 10. Interestingly, there is no effect whatsoever. In other words, process uncertainty is not an issue here and this is due to the low share of Oil GDP in total GDP. But the important result is that regardless of whether there is process uncertainty or not, average assets holdings are ten times higher compared to a model in which oil prices are assumed to be stationary. Thus, under permanent and transitory shocks, process uncertainty is not as relevant as explicitly considering that shocks can be temporary or permanent.

Table 10. Moments of the Markov switching model with imperfect information for the oil economy

\begin{tabular}{llllll}
\hline Moments & $\boldsymbol{P} \boldsymbol{B}$ & $\boldsymbol{B}$ & $\boldsymbol{C}$ & $\boldsymbol{T B}$ & $\boldsymbol{C A}$ \\
\hline Mean & 0.070 & -0.0524 & 1.003 & -0.003 & -0.0039 \\
Std Deviation & 0.200 & 6.6649 & 0.1687 & 9.3076 & 9.0799 \\
Autocorrelation & 0.380 & -0.0196 & 0.5604 & -0.4512 & -0.4486 \\
\hline & $\operatorname{corr}(B, Y)$ & $\operatorname{corr}(C, Y)$ & $\operatorname{corr}(B, C)$ & $\operatorname{corr}(T B, Y)$ & $\operatorname{corr}(C A, Y)$ \\
\hline Correlation & -0.6563 & 0.9895 & -0.6087 & 0.4728 & -0.2581 \\
\hline
\end{tabular}

\section{SENSITIVITY ANALYSIS}

It is interesting to assess whether the direction of the results presented above change if some key parameters change. We will focus our attention in comparing the models with and without process uncertainty (i.e., perfect versus imperfect information) in the non-stationary model presented above. First we check whether saving levels are higher under imperfect information (compared to the case of perfect information) as the share of commodity GDP is higher than 7 percent. Second, we check how the transition matrix between the two processes affects average assets holdings.

In order to assess how important is the magnitude of the share of GDP in our results we solved the model for a commodity GDP share of 20 percent and 66 percent. We find that when the share is 20 percent, it makes no difference whether you face process uncertainty or not, average assets holdings are the same. ${ }^{10}$ As Table 11 shows, for a share of 66 percent ${ }^{11}$, it happens that savings are higher under process uncertainty. This seems to suggest that when the proportion of output which is volatile is relatively high, then process uncertainty can (and should) matter a lot. The level of debt under perfect information is 12 percent higher compared to the case of process uncertainty.

\footnotetext{
${ }^{10}$ Results are not reported (but are available upon request) due to space considerations.

${ }^{11}$ Notice that many oil exporting countries (i.e., Saudi Arabia, Libya) have extremely high ratios of oil GDP.
} 
Table 11. Moments of the Markov switching model with higher share of commodity sector in GDP Perfect Information

\begin{tabular}{lccccc}
\hline Moments & $\boldsymbol{P Y}$ & $\boldsymbol{B}$ & $\boldsymbol{C}$ & $\boldsymbol{T B}$ & $\boldsymbol{C A}$ \\
\hline Mean & 0.660 & -0.4605 & 0.9856 & 0.0144 & 0.0063 \\
Std Deviation & 0.200 & 3.679 & 0.2012 & 3.1696 & 3.1165 \\
Autocorrelation & 0.380 & 0.575 & 0.4919 & 0.0015 & 0.0002 \\
\hline & $\operatorname{corr}(B, Y)$ & $\operatorname{corr}(C, Y)$ & $\operatorname{corr}(B, C)$ & $\operatorname{corr}(T B, Y)$ & $\operatorname{corr}(C A, Y)$ \\
\hline Correlation & -0.1994 & 0.9375 & -0.0332 & -0.2602 & -0.2459 \\
\hline
\end{tabular}

\begin{tabular}{lccccc}
\hline \multicolumn{7}{c}{ Imperfect Information } & & \\
\hline Moments & $\boldsymbol{P y}$ & $\boldsymbol{B}$ & $\boldsymbol{C}$ & $\boldsymbol{T B}$ & $\boldsymbol{C A}$ \\
\hline Mean & 0.660 & -0.4188 & 0.9859 & 0.0141 & 0.0067 \\
Std Deviation & 0.200 & 2.7395 & 0.1954 & 2.3092 & 2.2755 \\
Autocorrelation & 0.380 & 0.6172 & 0.5509 & 0.0439 & 0.0433 \\
\hline & $\operatorname{corr}(B, Y)$ & $\operatorname{corr}(C, Y)$ & $\operatorname{corr}(B, C)$ & $\operatorname{corr}(T B, Y)$ & $\operatorname{corr}(C A, Y)$ \\
\hline Correlation & -0.1656 & 0.9647 & -0.0477 & -0.3356 & -0.2821 \\
\hline
\end{tabular}

With respect to the transition matrix between regimes, it is easy to argue that for small shares of commodity GDP, it does affect average assets holdings, such that there is no difference between facing process uncertainty or perfect information (just compare the tables presented in the last section with the ones presented below). But for relatively high shares of commodity GDP, there are two interesting results (see Table 12). First, a transition matrix with all its elements equal to 0.5 provides no information at all about whether shocks are temporary or permanent, therefore we observe that for both perfect and imperfect information cases assets go up (i.e., debt go down). Second, it is always the case that under process uncertainty, average assets holdings are higher compared to the perfect info case. For a share of 66 percent, the debt level under perfect information is 42 percent higher compared to the case of process uncertainty. The transition matrix in the tables below has all its elements equal to 0.5 .

Table 12. Moments of the Markov switching model without learning $\left(m_{i j}=0.5\right)$

\begin{tabular}{lccccc}
\hline \multicolumn{7}{c}{ Perfect Information } \\
\hline Moments & $\boldsymbol{P Y}$ & $\boldsymbol{B}$ & $\boldsymbol{C}$ & $\boldsymbol{T B}$ & $\boldsymbol{C A}$ \\
\hline Mean & 0.660 & -0.3745 & 0.9795 & 0.0205 & 0.0139 \\
Std Deviation & 0.2828 & 101.9228 & 0.289 & 108.5891 & 106.7542 \\
Autocorrelation & 0.4515 & 0.501 & 0.5814 & -0.0357 & -0.0394 \\
\hline \multicolumn{7}{c}{$\operatorname{corr}(B, Y)$} & $\operatorname{corr}(C, Y)$ & $\operatorname{corr}(B, C)$ & $\operatorname{corr}(T B, Y)$ & $\operatorname{corr}(C A, Y)$ \\
\hline Correlation & -0.0862 & 0.9573 & 0.0152 & -0.1924 & -0.1489 \\
\hline \multicolumn{7}{c}{ Imperfect Information } \\
\hline Moments & $\boldsymbol{P y}$ & $\boldsymbol{B}$ & $\boldsymbol{C}$ & $\boldsymbol{T B}$ & $\boldsymbol{C A}$ \\
\hline Mean & 0.660 & -0.2672 & 0.9829 & 0.0171 & 0.0124 \\
Std Deviation & 0.2828 & 47.0486 & 0.2722 & 44.3206 & 43.9041 \\
Autocorrelation & 0.4515 & 0.5573 & 0.6499 & -0.0032 & -0.0085 \\
\hline \multicolumn{7}{c}{$\operatorname{corr}(B, Y)$} & $\operatorname{corr}(C, Y)$ & $\operatorname{corr}(B, C)$ & $\operatorname{corr}(T B, Y)$ & $\operatorname{corr}(C A, Y)$ \\
\hline Correlation & 0.0776 & 0.9876 & 0.1143 & -0.2733 & -0.1285 \\
\hline
\end{tabular}




\section{Policy Implications}

In a small open economy which chooses consumption levels and assets/debt positions across time in an optimizing framework, taking explicitly into account the existence of "parameter instability" seems to be crucial to determine optimal debt levels. Identification of temporary and permanent shocks poses serious challenges for policy makers because optimal reactions in terms of consumption/saving levels are completely different. For a small open economy with access to international capital markets, it is optimal to finance temporary shocks and adjust to permanent shocks.

The results of our simulations indicate that policy makers should be cautious when choosing policy rules. There has been a big debate regarding fiscal policy rules, both in policy and academic circles, with mixed experiences. The case of Chile, with the copper stabilization fund and the explicit fiscal rule is a successful example of countercyclical fiscal policy in Latin America. In terms of the model presented above, one could think about optimal fiscal policy financed with external debt, as has been the case in many developing countries. Setting a particular target level for external debt, a debt ceiling, or a balanced budget rule is not optimal. On the contrary, an optimal rule should be based first, on the current level of external debt, second, the state of the economy (i.e. good times or bad times) and third, the policy maker's "beliefs" about the state of the economy or the policy maker's "beliefs" about the persistence of shocks at a particular point in time. In other words, optimal fiscal rules should be state contingent and should put some kind of weights, or probabilities of regime shifts that make current price levels more or less permanent, as well as more volatile. It would be a big mistake to "take a stand", and assume, for simplicity, that prices follows a simple process and that there are no regime switches.

Moreover, wrong perceptions (or assumptions) about the nature of the process could lead to substantial over or under spending with the associated high or (unnecessarily) low levels of debt.

In practice, though, state contingent policy rules are difficult to implement because oftentimes they are hard to explain to politicians, congressmen, or the public in general. They are also costly, because they imply continuous monitoring and assessments of the state of the economy and commodity prices, as well as continuous forecasting and prediction about output gaps or persistence and volatility of the relevant stochastic process (i.e. commodity prices) driving economic fluctuations. In spite of this, and given actual uncertainty about the true stochastic process, we want to emphasise that forecasts or predictions are important and necessary in order to set and implement sensible saving or debt rules over time. This, of course, has immediate consequences on consumption volatility, which is an important concern in many developing countries.

In terms of commodities stabilization funds, the model suggests some room for them, since accumulating a buffer stock of foreign assets can help stabilize economic fluctuations over time and therefore increase welfare. 


\section{CONCLUSIONS}

In this paper, we have shown that trends in commodity prices change over time for almost all commodities considered in our sample. At the same time, the volatility of commodity prices also displays substantial changes over time. Furthermore, to assess the relative importance of parameter instability and process uncertainty, we showed that the permanent component in commodity prices can, in some cases, account for more than half of the total volatility. Regarding the cyclical (transitory) component, we estimated a Markov switching model and found that it can better fit the data compared to the standard AR(1) model, usually used in the literature. Based on these findings, we build a dynamic stochastic general equilibrium model with parameter instability and informational frictions to explicitly capture uncertainty about the underlying process in terms of persistence and volatility. This model has two particular features compared to the standard intertemporal model for a small open economy.

First, we explicitly model changes in persistence of shocks across time. This adds an extra layer of uncertainty (i.e., process uncertainty) on top of the standard one, regarding the particular realization of the shock. Second, agents have a learning technology and use it to infer probabilities about the nature of the process. In this way they form the appropriate expectations and are able to choose optimally, how much to borrow/lend and therefore how much to consume over time. We focus our attention in assessing first, how this model compares to the standard textbook model of a small open economy and second, the effects of process uncertainty on optimal saving (debt) levels. We show that parameter instability in the stochastic process implies that optimal saving levels (debt holdings) should be higher (lower) compared to a process with fixed parameters. Imperfect information about the stochastic process matters when commodity GDP shares are high, therefore informational frictions (i.e., imperfect information) imply that optimal saving (debt) levels should be higher (lower) compared to the perfect information case.

If policymakers suffer from "misperception", they will use inappropriate policy rules. They will under/over save compared to the case in which they acknowledge the existence of differences in the regime of the stochastic process of commodity prices. The consequences of misperception can be devastating for commodity exporters. They could end up overspending and accumulating high (and often times unsustainable) levels of debt, and this could eventually create other problems like pro-cyclical fiscal spending and default. On the other extreme they could end up over-saving with the associated and forgone opportunity cost of funds. Either extreme is dangerous and that is why it is important to take into account process uncertainty at the time of making saving and spending decisions at government levels. This type of uncertainty can also have major effects on the fiscal and external balances and that is precisely why it is important to incorporate it when thinking about optimal policy. 


\section{APPENDIX}

Table A.1 Descriptive statistics of commodity prices

\begin{tabular}{|c|c|c|c|c|c|c|}
\hline Commodity & & $57-69$ & $70-79$ & 80-89 & 90-99 & 00-07 \\
\hline \multirow[t]{4}{*}{ ALUMINUM } & Mean & 16.266 & 16.192 & 14.682 & 11.840 & 12.231 \\
\hline & SD & 0.467 & 2.248 & 4.486 & 1.538 & 2.093 \\
\hline & $\mathrm{SD} /$ Mean & 0.029 & 0.139 & 0.306 & 0.130 & 0.171 \\
\hline & Autocorrelation & 0.108 & 0.775 & 0.345 & 0.132 & 0.742 \\
\hline \multirow[t]{4}{*}{ BEEF } & Mean & 1.164 & 1.457 & 1.076 & 0.814 & 0.709 \\
\hline & SD & 0.224 & 0.317 & 0.128 & 0.173 & 0.044 \\
\hline & SD/Mean & 0.192 & 0.218 & 0.119 & 0.212 & 0.062 \\
\hline & Autocorrelation & 0.911 & 0.478 & 0.732 & 0.887 & -0.228 \\
\hline \multirow[t]{4}{*}{ BUTTER } & Mean & 1.039 & 0.927 & 0.765 & 0.705 & 0.529 \\
\hline & SD & 0.148 & 0.144 & 0.157 & 0.080 & 0.070 \\
\hline & $\mathrm{SD} /$ Mean & 0.142 & 0.155 & 0.205 & 0.114 & 0.132 \\
\hline & Autocorrelation & 0.374 & 0.245 & 0.746 & 0.274 & 0.126 \\
\hline \multirow[t]{4}{*}{ COCOA BEANS } & Mean & 19.315 & 30.657 & 19.943 & 10.953 & 10.320 \\
\hline & SD & 5.409 & 14.856 & 4.834 & 1.469 & 2.242 \\
\hline & SD/Mean & 0.280 & 0.485 & 0.242 & 0.134 & 0.217 \\
\hline & Autocorrelation & 0.611 & 0.719 & 0.602 & 0.206 & 0.333 \\
\hline \multirow[t]{4}{*}{ CACAO } & Mean & 17.564 & 29.900 & 18.621 & 10.251 & 11.304 \\
\hline & SD & 5.146 & 15.831 & 4.239 & 1.687 & 2.342 \\
\hline & $\mathrm{SD} /$ Mean & 0.293 & 0.530 & 0.228 & 0.165 & 0.207 \\
\hline & Autocorrelation & 0.609 & 0.603 & 0.488 & 0.573 & 0.096 \\
\hline \multirow[t]{4}{*}{ COCONUT OIL:PHILIPPINES } & Mean & 9.786 & 10.226 & 6.034 & 4.857 & 3.723 \\
\hline & SD & 1.225 & 3.713 & 2.386 & 1.036 & 0.900 \\
\hline & $\mathrm{SD} /$ Mean & 0.125 & 0.363 & 0.395 & 0.213 & 0.242 \\
\hline & Autocorrelation & 0.245 & -0.046 & 0.259 & 0.577 & 0.297 \\
\hline \multirow[t]{4}{*}{ COFFEE:OTHER MILDS } & Mean & 1.336 & 1.807 & 1.376 & 0.932 & 0.588 \\
\hline & SD & 0.227 & 0.804 & 0.279 & 0.298 & 0.118 \\
\hline & $\mathrm{SD} /$ Mean & 0.170 & 0.445 & 0.203 & 0.320 & 0.201 \\
\hline & Autocorrelation & 0.729 & 0.571 & -0.127 & 0.361 & 0.588 \\
\hline \multirow[t]{4}{*}{ COFFEE:BRAZIL (NEW YORK) } & Mean & 1.261 & 1.952 & 1.532 & 0.868 & 0.509 \\
\hline & SD & 0.226 & 0.894 & 0.498 & 0.290 & 0.133 \\
\hline & $\mathrm{SD} /$ Mean & 0.179 & 0.458 & 0.325 & 0.334 & 0.262 \\
\hline & Autocorrelation & 0.596 & 0.496 & 0.208 & 0.453 & 0.574 \\
\hline \multirow[t]{4}{*}{ COFFEE:BRAZIL: US CENTS/LB } & Mean & 1.066 & 1.538 & 1.088 & 0.714 & 0.440 \\
\hline & SD & 0.166 & 0.729 & 0.374 & 0.266 & 0.131 \\
\hline & $\mathrm{SD} /$ Mean & 0.156 & 0.474 & 0.344 & 0.372 & 0.298 \\
\hline & Autocorrelation & 0.580 & 0.570 & -0.195 & 0.518 & 0.561 \\
\hline \multirow[t]{4}{*}{ COFFEE:UGANDA } & Mean & 1.039 & 1.637 & 1.157 & 0.623 & 0.321 \\
\hline & $\mathrm{SD}$ & 0.139 & 0.792 & 0.282 & 0.225 & 0.104 \\
\hline & $\mathrm{SD} /$ Mean & 0.134 & 0.484 & 0.244 & 0.362 & 0.323 \\
\hline & Autocorrelation & 0.494 & 0.569 & 0.256 & 0.474 & 0.753 \\
\hline \multirow[t]{4}{*}{ COPPER } & Mean & 28.218 & 28.031 & 18.035 & 18.281 & 21.909 \\
\hline & SD & 9.996 & 7.891 & 4.820 & 3.603 & 12.509 \\
\hline & SD/Mean & 0.354 & 0.282 & 0.267 & 0.197 & 0.571 \\
\hline & Autocorrelation & 0.820 & 0.420 & 0.613 & 0.494 & 0.864 \\
\hline \multirow[t]{4}{*}{ COPRA:PHILIPPINES } & Mean & 6.127 & 6.509 & 3.934 & 3.145 & 2.456 \\
\hline & SD & 0.780 & 2.608 & 1.365 & 0.602 & 0.635 \\
\hline & $\mathrm{SD} /$ Mean & 0.127 & 0.401 & 0.347 & 0.192 & 0.258 \\
\hline & Autocorrelation & 0.132 & 0.022 & 0.264 & 0.483 & 0.295 \\
\hline \multirow[t]{4}{*}{ COTTON:LIVERPOOL } & Mean & 0.904 & 1.046 & 0.729 & 0.600 & 0.388 \\
\hline & SD & 0.058 & 0.190 & 0.161 & 0.114 & 0.046 \\
\hline & $\mathrm{SD} /$ Mean & 0.064 & 0.182 & 0.221 & 0.190 & 0.119 \\
\hline & Autocorrelation & 0.239 & 0.110 & 0.494 & 0.401 & 0.024 \\
\hline FISHMEAL & Mean & 8.929 & 12.651 & 7.391 & 4.460 & 4.978 \\
\hline & SD & 1.981 & 4.478 & 1.945 & 0.874 & 1.176 \\
\hline & SD/Mean & 0.222 & 0.354 & 0.263 & 0.196 & 0.236 \\
\hline & Autocorrelation & 0.419 & 0.078 & 0.675 & 0.244 & 0.770 \\
\hline GROUNDNUTS:NIGERIA & Mean & 5.750 & 8.059 & 9.394 & 7.154 & 5.708 \\
\hline & SD & 0.495 & 2.253 & 3.308 & 1.258 & 0.699 \\
\hline & SD/Mean & 0.086 & 0.280 & 0.352 & 0.176 & 0.122 \\
\hline & Autocorrelation & 0.038 & 0.086 & 0.778 & 0.161 & -0.268 \\
\hline GROUNDNUT OIL & Mean & 9.412 & 12.888 & 7.462 & 7.232 & 6.630 \\
\hline & SD & 1.019 & 2.852 & 2.068 & 1.055 & 1.495 \\
\hline & SD/Mean & 0.108 & 0.221 & 0.277 & 0.146 & 0.226 \\
\hline & Autocorrelation & 0.105 & -0.002 & 0.359 & 0.119 & 0.246 \\
\hline
\end{tabular}




\begin{tabular}{|c|c|c|c|c|c|c|}
\hline \multirow[t]{4}{*}{ HIDES } & Mean & 0.418 & 0.580 & 0.587 & 0.679 & 0.507 \\
\hline & SD & 0.083 & 0.194 & 0.163 & 0.059 & 0.095 \\
\hline & SD/Mean & 0.198 & 0.334 & 0.278 & 0.087 & 0.187 \\
\hline & Autocorrelation & 0.018 & 0.386 & 0.852 & 0.470 & 0.871 \\
\hline \multirow[t]{4}{*}{ IRON ORE:BRAZIL (US CENTS/DMTU) } & Mean & 0.508 & 0.345 & 0.270 & 0.249 & 0.316 \\
\hline & SD & 0.110 & 0.039 & 0.031 & 0.028 & 0.120 \\
\hline & SD/Mean & 0.217 & 0.112 & 0.116 & 0.112 & 0.380 \\
\hline & Autocorrelation & 0.915 & 0.002 & 0.642 & 0.719 & 0.897 \\
\hline \multirow[t]{4}{*}{ JUTE:BANGLADESH } & Mean & 7.595 & 6.155 & 3.549 & 2.690 & 1.997 \\
\hline & $\mathrm{SD}$ & 1.529 & 1.034 & 1.012 & 0.550 & 0.245 \\
\hline & $\mathrm{SD} /$ Mean & 0.201 & 0.168 & 0.285 & 0.204 & 0.123 \\
\hline & Autocorrelation & 0.222 & 0.744 & 0.218 & 0.394 & 0.439 \\
\hline \multirow[t]{4}{*}{ LAMB:NEW ZEALAND } & Mean & 0.933 & 1.208 & 1.019 & 1.009 & 1.014 \\
\hline & SD & 0.084 & 0.175 & 0.206 & 0.097 & 0.110 \\
\hline & $\mathrm{SD} / \mathrm{Mean}$ & 0.090 & 0.145 & 0.202 & 0.096 & 0.109 \\
\hline & Autocorrelation & 0.199 & 0.577 & 0.854 & -0.017 & 0.587 \\
\hline \multirow[t]{4}{*}{ LEAD } & Mean & 7.114 & 9.170 & 5.717 & 4.859 & 6.138 \\
\hline & $\mathrm{SD}$ & 1.451 & 2.548 & 1.919 & 1.013 & 3.917 \\
\hline & SD/Mean & 0.204 & 0.278 & 0.336 & 0.208 & 0.638 \\
\hline & Autocorrelation & 0.478 & 0.259 & 0.776 & 0.254 & 0.903 \\
\hline \multirow[t]{4}{*}{ LINSEED OIL } & Mean & 7.445 & 9.070 & 5.495 & 4.526 & 4.695 \\
\hline & SD & 1.128 & 4.772 & 1.377 & 0.888 & 1.479 \\
\hline & SD/Mean & 0.152 & 0.526 & 0.251 & 0.196 & 0.315 \\
\hline & Autocorrelation & 0.773 & 0.471 & 0.412 & -0.004 & 0.434 \\
\hline \multirow[t]{4}{*}{ MAIZE: US } & Mean & 1.611 & 1.741 & 1.116 & 0.924 & 0.740 \\
\hline & SD & 0.121 & 0.372 & 0.224 & 0.148 & 0.098 \\
\hline & SD/Mean & 0.075 & 0.214 & 0.200 & 0.160 & 0.133 \\
\hline & Autocorrelation & 0.488 & 0.554 & 0.620 & 0.273 & 0.133 \\
\hline \multirow[t]{4}{*}{ MAIZE:Thailand } & Mean & 1.677 & 1.846 & 1.242 & 1.473 & 1.411 \\
\hline & SD & 0.118 & 0.395 & 0.286 & 0.458 & 0.451 \\
\hline & SD/Mean & 0.070 & 0.214 & 0.230 & 0.311 & 0.319 \\
\hline & Autocorrelation & 0.515 & 0.482 & 0.769 & 0.539 & -0.777 \\
\hline \multirow[t]{4}{*}{ NICKEL } & Mean & 54.933 & 75.868 & 65.482 & 56.730 & 97.575 \\
\hline & $\mathrm{SD}$ & 3.752 & 4.395 & 32.187 & 11.960 & 57.291 \\
\hline & SD/Mean & 0.068 & 0.058 & 0.492 & 0.211 & 0.587 \\
\hline & Autocorrelation & 0.825 & -0.073 & 0.561 & 0.521 & 0.931 \\
\hline \multirow[t]{4}{*}{ PALM OIL:MALAYSIA } & Mean & 6.238 & 6.818 & 4.325 & 3.699 & 2.737 \\
\hline & $\mathrm{SD}$ & 1.088 & 1.521 & 1.193 & 0.821 & 0.646 \\
\hline & $\mathrm{SD} /$ Mean & 0.174 & 0.223 & 0.276 & 0.222 & 0.236 \\
\hline & Autocorrelation & 0.665 & 0.273 & 0.413 & 0.450 & 0.224 \\
\hline \multirow[t]{4}{*}{ PETROLEUM:AVERAGE CRUDE PRICE } & Mean & 0.057 & 0.159 & 0.251 & 0.150 & 0.274 \\
\hline & $\mathrm{SD}$ & 0.004 & 0.103 & 0.092 & 0.025 & 0.093 \\
\hline & $\mathrm{SD} /$ Mean & 0.078 & 0.644 & 0.366 & 0.163 & 0.340 \\
\hline & Autocorrelation & 0.922 & 0.649 & 0.865 & 0.362 & 0.934 \\
\hline \multirow[t]{4}{*}{ PETROLEUM:DUBAI } & Mean & 0.057 & 0.156 & 0.243 & 0.137 & 0.256 \\
\hline & $\mathrm{SD}$ & 0.004 & 0.102 & 0.098 & 0.021 & 0.091 \\
\hline & $\mathrm{SD} /$ Mean & 0.067 & 0.655 & 0.404 & 0.152 & 0.355 \\
\hline & Autocorrelation & 0.894 & 0.655 & 0.881 & 0.087 & 0.932 \\
\hline PETROLEUM:UK BRENT & Mean & 0.067 & 0.182 & 0.260 & 0.151 & 0.278 \\
\hline & $\mathrm{SD}$ & 0.003 & 0.105 & 0.100 & 0.027 & 0.097 \\
\hline & $\mathrm{SD} /$ Mean & 0.048 & 0.575 & 0.386 & 0.180 & 0.348 \\
\hline & Autocorrelation & 0.333 & 0.602 & 0.887 & 0.447 & 0.935 \\
\hline PHOSPHATE ROCK:MOROCCO & Mean & 0.391 & 0.523 & 0.386 & 0.322 & 0.309 \\
\hline & $\mathrm{SD}$ & 0.041 & 0.309 & 0.074 & 0.036 & 0.047 \\
\hline & $\mathrm{SD} /$ Mean & 0.105 & 0.591 & 0.193 & 0.110 & 0.152 \\
\hline & Autocorrelation & 0.735 & 0.489 & 0.862 & 0.615 & -0.136 \\
\hline POTASH & Mean & 0.802 & 0.949 & 0.867 & 0.920 & 0.945 \\
\hline & $\mathrm{SD}$ & 0.092 & 0.185 & 0.198 & 0.038 & 0.119 \\
\hline & $\mathrm{SD} /$ Mean & 0.115 & 0.195 & 0.229 & 0.041 & 0.126 \\
\hline & Autocorrelation & 0.454 & 0.358 & 0.730 & -0.036 & 0.818 \\
\hline RICE:THAILAND (BANGKOK) & Mean & 4.779 & 5.186 & 2.927 & 2.339 & 1.625 \\
\hline & SD & 0.766 & 2.033 & 1.075 & 0.225 & 0.228 \\
\hline & SD/Mean & 0.160 & 0.392 & 0.367 & 0.096 & 0.140 \\
\hline & Autocorrelation & 0.635 & 0.406 & 0.783 & 0.164 & 0.756 \\
\hline RICE:THAILAND & Mean & 3.794 & 4.138 & 2.593 & 2.663 & 1.887 \\
\hline & SD & 0.483 & 1.848 & 0.768 & 0.536 & 0.210 \\
\hline & SD/Mean & 0.127 & 0.447 & 0.296 & 0.201 & 0.111 \\
\hline & Autocorrelation & 0.503 & 0.335 & 0.710 & -0.270 & 0.438 \\
\hline
\end{tabular}




\begin{tabular}{|c|c|c|c|c|c|c|}
\hline \multirow[t]{4}{*}{ RUBBER:MALAYSIA } & Mean & 0.774 & 0.554 & 0.455 & 0.366 & 0.383 \\
\hline & $\mathrm{SD}$ & 0.183 & 0.122 & 0.110 & 0.105 & 0.153 \\
\hline & $\mathrm{SD} /$ Mean & 0.236 & 0.221 & 0.243 & 0.288 & 0.400 \\
\hline & Autocorrelation & 0.784 & 0.257 & 0.441 & 0.617 & 0.926 \\
\hline \multirow[t]{4}{*}{ RUBBER:THAILAND } & Mean & 0.693 & 0.500 & 0.424 & 0.334 & 0.323 \\
\hline & SD & 0.156 & 0.111 & 0.103 & 0.093 & 0.125 \\
\hline & $\mathrm{SD} /$ Mean & 0.225 & 0.223 & 0.244 & 0.278 & 0.385 \\
\hline & Autocorrelation & 0.702 & 0.300 & 0.396 & 0.615 & 0.912 \\
\hline \multirow[t]{4}{*}{ SHRIMP: U.S. GULF } & Mean & 0.058 & 0.110 & 0.121 & 0.114 & 0.083 \\
\hline & SD & 0.017 & 0.024 & 0.016 & 0.012 & 0.023 \\
\hline & $\mathrm{SD} /$ Mean & 0.289 & 0.219 & 0.131 & 0.103 & 0.276 \\
\hline & Autocorrelation & 0.816 & 0.482 & -0.158 & 0.610 & 0.922 \\
\hline \multirow[t]{4}{*}{ SILVER } & Mean & 3.832 & 7.119 & 8.998 & 3.966 & 4.766 \\
\hline & SD & 1.034 & 2.927 & 5.333 & 0.379 & 1.707 \\
\hline & $\mathrm{SD} /$ Mean & 0.270 & 0.411 & 0.593 & 0.096 & 0.358 \\
\hline & Autocorrelation & 0.783 & 0.602 & 0.646 & 0.324 & 0.867 \\
\hline \multirow[t]{4}{*}{ SISAL:EAST AFRICA } & Mean & 7.188 & 8.735 & 5.847 & 5.713 & 5.307 \\
\hline & SD & 2.338 & 4.521 & 1.058 & 0.750 & 0.371 \\
\hline & $\mathrm{SD} /$ Mean & 0.325 & 0.518 & 0.181 & 0.131 & 0.070 \\
\hline & Autocorrelation & 0.621 & 0.407 & 0.858 & 0.344 & 0.337 \\
\hline \multirow[t]{4}{*}{ SORGHUM:US } & Mean & 1.407 & 1.634 & 1.061 & 0.882 & 0.746 \\
\hline & $\mathrm{SD}$ & 0.118 & 0.338 & 0.227 & 0.128 & 0.097 \\
\hline & SD/Mean & 0.084 & 0.207 & 0.213 & 0.145 & 0.131 \\
\hline & Autocorrelation & 0.660 & 0.605 & 0.748 & 0.302 & 0.131 \\
\hline \multirow[t]{4}{*}{ SOYBEANS: US } & Mean & 3.019 & 3.768 & 2.345 & 1.866 & 1.528 \\
\hline & $\mathrm{SD}$ & 0.279 & 0.922 & 0.365 & 0.225 & 0.242 \\
\hline & SD/Mean & 0.092 & 0.245 & 0.156 & 0.121 & 0.158 \\
\hline & Autocorrelation & 0.404 & 0.238 & 0.342 & 0.295 & 0.098 \\
\hline \multirow[t]{4}{*}{ SOYBEAN MEAL } & Mean & 2.353 & 3.122 & 2.019 & 1.694 & 1.435 \\
\hline & $\mathrm{SD}$ & 0.193 & 1.079 & 0.351 & 0.289 & 0.176 \\
\hline & $\mathrm{SD} /$ Mean & 0.082 & 0.346 & 0.174 & 0.170 & 0.122 \\
\hline & Autocorrelation & 0.234 & 0.010 & 0.424 & 0.242 & 0.037 \\
\hline \multirow[t]{4}{*}{ SOYBEAN OIL } & Mean & 6.454 & 7.578 & 4.807 & 4.172 & 3.392 \\
\hline & SD & 1.479 & 2.153 & 0.953 & 0.531 & 0.689 \\
\hline & SD/Mean & 0.229 & 0.284 & 0.198 & 0.127 & 0.203 \\
\hline & Autocorrelation & 0.571 & 0.173 & 0.240 & 0.142 & 0.404 \\
\hline \multirow[t]{4}{*}{ SUGAR: US CENTS/LB } & Mean & 0.130 & 0.217 & 0.109 & 0.099 & 0.061 \\
\hline & SD & 0.032 & 0.146 & 0.057 & 0.022 & 0.012 \\
\hline & $\mathrm{SD} /$ Mean & 0.245 & 0.669 & 0.523 & 0.224 & 0.190 \\
\hline & Autocorrelation & 0.357 & 0.505 & 0.819 & 0.570 & 0.231 \\
\hline \multirow[t]{4}{*}{ SUGAR:EU } & Mean & 0.173 & 0.196 & 0.192 & 0.233 & 0.191 \\
\hline & $\mathrm{SD}$ & 0.012 & 0.046 & 0.029 & 0.012 & 0.008 \\
\hline & SD/Mean & 0.071 & 0.234 & 0.149 & 0.051 & 0.044 \\
\hline & Autocorrelation & 0.760 & 0.686 & 0.575 & 0.558 & 0.225 \\
\hline \multirow[t]{4}{*}{ SUGAR:CARIBBEAN } & Mean & 0.111 & 0.208 & 0.108 & 0.086 & 0.060 \\
\hline & $\mathrm{SD}$ & 0.062 & 0.145 & 0.083 & 0.018 & 0.013 \\
\hline & $\mathrm{SD} /$ Mean & 0.553 & 0.694 & 0.767 & 0.207 & 0.220 \\
\hline & Autocorrelation & 0.353 & 0.438 & 0.838 & 0.508 & 0.168 \\
\hline SUGAR:US & Mean & 0.193 & 0.257 & 0.219 & 0.181 & 0.144 \\
\hline & $\mathrm{SD}$ & 0.016 & 0.119 & 0.041 & 0.009 & 0.014 \\
\hline & $\mathrm{SD} /$ Mean & 0.085 & 0.461 & 0.187 & 0.048 & 0.098 \\
\hline & Autocorrelation & 0.258 & 0.337 & -0.301 & 0.593 & 0.771 \\
\hline SUGAR:PHILIPPINES & Mean & 0.186 & 0.219 & 0.163 & 0.155 & 0.112 \\
\hline & SD & 0.021 & 0.118 & 0.026 & 0.019 & 0.023 \\
\hline & $\mathrm{SD} /$ Mean & 0.110 & 0.539 & 0.159 & 0.120 & 0.206 \\
\hline & Autocorrelation & 0.036 & 0.538 & 0.412 & 0.259 & 0.520 \\
\hline TEA & Mean & 4.053 & 2.823 & 2.108 & 1.645 & 1.442 \\
\hline & SD & 0.612 & 0.525 & 0.502 & 0.205 & 0.189 \\
\hline & SD/Mean & 0.151 & 0.186 & 0.238 & 0.125 & 0.131 \\
\hline & Autocorrelation & 0.941 & 0.162 & 0.197 & 0.510 & 0.332 \\
\hline TEA:SRI LANKA & Mean & 3.492 & 2.483 & 1.973 & 1.825 & 1.736 \\
\hline & SD & 0.501 & 0.400 & 0.419 & 0.259 & 0.087 \\
\hline & SD/Mean & 0.143 & 0.161 & 0.213 & 0.142 & 0.050 \\
\hline & Autocorrelation & 0.992 & 0.257 & 0.363 & 0.578 & -0.238 \\
\hline TIMBER:HARDWOOD LOGS:SARAWAK & Mean & 1.031 & 1.400 & 1.208 & 1.920 & 1.356 \\
\hline & SD & 0.132 & 0.324 & 0.319 & 0.615 & 0.119 \\
\hline & $\mathrm{SD} /$ Mean & 0.128 & 0.231 & 0.264 & 0.320 & 0.088 \\
\hline & Autocorrelation & 0.751 & 0.180 & 0.435 & 0.415 & 0.239 \\
\hline
\end{tabular}




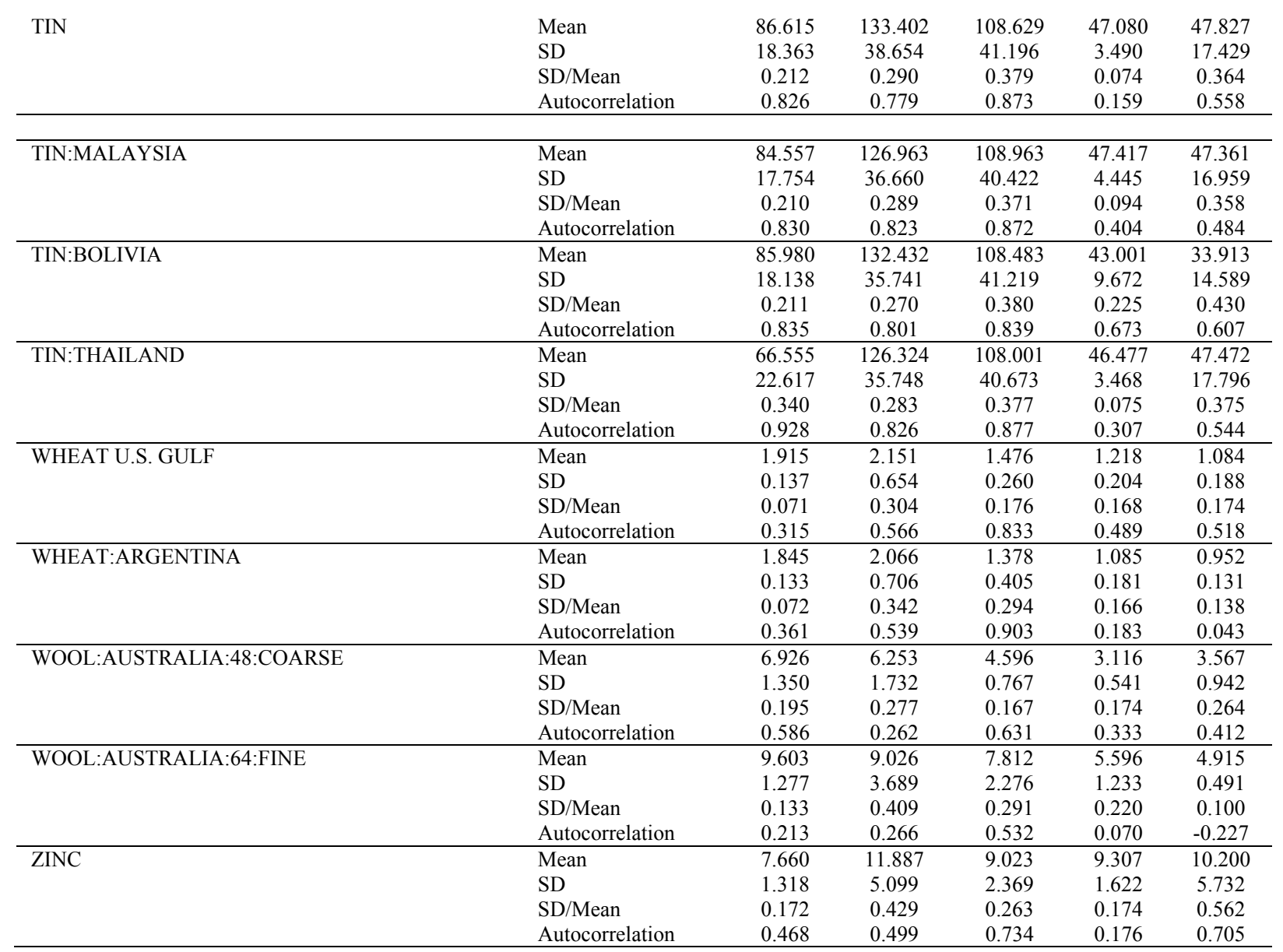


Table A.2 Variance Ratios

\begin{tabular}{|c|c|c|c|c|c|c|c|}
\hline & \multirow[t]{2}{*}{ Commodity Price } & \multicolumn{6}{|c|}{ Lags $(k)$} \\
\hline & & 2 & 4 & 8 & 10 & 12 & 20 \\
\hline 1 & ALUMINUM & 0.972 & 0.649 & 0.189 & 0.195 & 0.275 & 0.157 \\
\hline 2 & BEEF:AUSTRALIA & 0.985 & 0.845 & 0.733 & 0.665 & 0.590 & 0.391 \\
\hline 3 & BUTTER:NEW ZEALAND & 0.761 & 0.545 & 0.241 & 0.191 & 0.161 & 0.147 \\
\hline 4 & COCOA BEANS & 1.040 & 0.796 & 0.572 & 0.613 & 0.712 & 0.362 \\
\hline 5 & CACAO: US\$/MT & 0.967 & 0.769 & 0.554 & 0.581 & 0.676 & 0.297 \\
\hline 6 & COCONUT OIL:PHILIPPINES & 0.516 & 0.259 & 0.196 & 0.150 & 0.174 & 0.083 \\
\hline 7 & COFFEE:OTHER MILDS & 0.908 & 0.829 & 0.352 & 0.336 & 0.383 & 0.203 \\
\hline 8 & COFFEE:BRAZIL (NEW YORK) & 0.920 & 0.871 & 0.442 & 0.434 & 0.472 & 0.317 \\
\hline 9 & COFFEE:BRAZIL: US CENTS/LB & 0.915 & 0.848 & 0.305 & 0.290 & 0.344 & 0.169 \\
\hline 10 & COFFEE:UGANDA & 1.169 & 1.053 & 0.520 & 0.517 & 0.586 & 0.418 \\
\hline 11 & COPPER & 1.110 & 0.962 & 0.648 & 0.565 & 0.480 & 0.274 \\
\hline 12 & COPRA:PHILIPPINES & 0.542 & 0.256 & 0.186 & 0.147 & 0.177 & 0.091 \\
\hline 13 & COTTON:LIVERPOOL & 0.584 & 0.505 & 0.422 & 0.364 & 0.300 & 0.172 \\
\hline 14 & FISHMEAL & 0.562 & 0.499 & 0.371 & 0.362 & 0.422 & 0.263 \\
\hline 15 & GROUNDNUTS:NIGERIA & 0.440 & 0.411 & 0.265 & 0.297 & 0.271 & 0.224 \\
\hline 16 & GROUNDNUT OIL & 0.623 & 0.406 & 0.359 & 0.345 & 0.269 & 0.137 \\
\hline 17 & HIDES & 0.685 & 0.483 & 0.372 & 0.247 & 0.206 & 0.142 \\
\hline 18 & IRON ORE:BRAZIL & 1.028 & 0.855 & 0.547 & 0.581 & 0.450 & 0.423 \\
\hline 19 & JUTE:BANGLADESH & 0.688 & 0.267 & 0.297 & 0.172 & 0.191 & 0.124 \\
\hline 20 & LAMB:NEW ZEALAND & 0.937 & 0.688 & 0.452 & 0.492 & 0.400 & 0.235 \\
\hline 21 & LEAD & 1.022 & 0.810 & 0.359 & 0.372 & 0.379 & 0.314 \\
\hline 22 & LINSEED OIL & 0.919 & 0.466 & 0.316 & 0.314 & 0.279 & 0.103 \\
\hline 23 & MAIZE: US & 0.831 & 0.568 & 0.409 & 0.341 & 0.348 & 0.144 \\
\hline 24 & MAIZE: Thailand & 0.407 & 0.339 & 0.242 & 0.217 & 0.180 & 0.072 \\
\hline 25 & NICKEL & 0.916 & 0.841 & 0.516 & 0.369 & 0.349 & 0.260 \\
\hline 26 & PALM OIL:MALAYSIA & 0.615 & 0.485 & 0.314 & 0.269 & 0.243 & 0.114 \\
\hline 27 & PETROLEUM:AVERAGE CRUDE PRICE & 0.977 & 0.961 & 1.181 & 1.140 & 1.090 & 0.594 \\
\hline 28 & PETROLEUM:DUBAI & 0.895 & 0.906 & 1.137 & 1.090 & 1.035 & 0.557 \\
\hline 29 & PETROLEUM:UK BRENT & 0.865 & 0.891 & 1.086 & 1.044 & 1.012 & 0.608 \\
\hline 30 & PHOSPHATE ROCK:MOROCCO & 0.957 & 0.612 & 0.377 & 0.356 & 0.330 & 0.133 \\
\hline 31 & POTASH & 0.853 & 0.486 & 0.313 & 0.290 & 0.227 & 0.127 \\
\hline 32 & RICE:THAILAND (BANGKOK) & 1.107 & 0.699 & 0.553 & 0.459 & 0.396 & 0.221 \\
\hline 33 & RICE:THAILAND & 0.832 & 0.509 & 0.402 & 0.312 & 0.239 & 0.111 \\
\hline 34 & RUBBER:MALAYSIA & 0.994 & 0.876 & 0.355 & 0.285 & 0.283 & 0.199 \\
\hline 35 & RUBBER:THAILAND & 0.983 & 0.848 & 0.324 & 0.263 & 0.269 & 0.189 \\
\hline 36 & SHRIMP: U.S. GULF & 0.623 & 0.723 & 0.599 & 0.546 & 0.531 & 0.555 \\
\hline 37 & SILVER & 0.930 & 0.768 & 0.811 & 0.804 & 0.805 & 0.720 \\
\hline 38 & SISAL:EAST AFRICA & 1.091 & 0.819 & 0.419 & 0.285 & 0.272 & 0.137 \\
\hline 39 & SORGHUM:US & 0.919 & 0.640 & 0.531 & 0.466 & 0.483 & 0.222 \\
\hline 40 & SOYBEANS: US & 0.721 & 0.531 & 0.386 & 0.355 & 0.366 & 0.187 \\
\hline 41 & SOYBEAN MEAL & 0.546 & 0.365 & 0.291 & 0.271 & 0.259 & 0.117 \\
\hline 42 & SOYBEAN OIL & 0.632 & 0.434 & 0.250 & 0.259 & 0.194 & 0.103 \\
\hline 43 & SUGAR: US CENTS/LB & 0.968 & 0.626 & 0.478 & 0.403 & 0.386 & 0.142 \\
\hline 44 & SUGAR:EU & 0.989 & 1.040 & 0.791 & 0.541 & 0.309 & 0.235 \\
\hline 45 & SUGAR:CARIBBEAN & 0.977 & 0.718 & 0.476 & 0.391 & 0.347 & 0.171 \\
\hline 46 & SUGAR:US & 0.697 & 0.357 & 0.264 & 0.225 & 0.232 & 0.130 \\
\hline 47 & SUGAR:PHILIPPINES & 0.937 & 0.504 & 0.355 & 0.263 & 0.213 & 0.085 \\
\hline 48 & TEA & 0.669 & 0.429 & 0.300 & 0.269 & 0.160 & 0.063 \\
\hline 49 & TEA:SRI LANKA & 0.823 & 0.474 & 0.416 & 0.339 & 0.220 & 0.140 \\
\hline 50 & TIMBER:HARDWOOD & 0.705 & 0.634 & 0.505 & 0.415 & 0.272 & 0.138 \\
\hline 51 & TIN & 0.869 & 0.936 & 0.949 & 0.957 & 1.007 & 0.923 \\
\hline 52 & TIN:MALAYSIA & 0.847 & 0.927 & 0.952 & 0.942 & 0.988 & 0.937 \\
\hline 53 & TIN:BOLIVIA & 0.822 & 0.871 & 0.891 & 0.840 & 0.921 & 0.979 \\
\hline 54 & WHEAT U.S. GULF & 1.094 & 0.675 & 0.436 & 0.372 & 0.349 & 0.153 \\
\hline 55 & WHEAT:ARGENTINA & 1.018 & 0.635 & 0.467 & 0.448 & 0.376 & 0.144 \\
\hline 56 & WOOL:AUSTRALIA:48:COARSE & 1.019 & 0.694 & 0.292 & 0.321 & 0.235 & 0.158 \\
\hline 57 & WOOL:AUSTRALIA:64:FINE & 0.823 & 0.484 & 0.233 & 0.216 & 0.191 & 0.078 \\
\hline 58 & ZINC & 1.033 & 0.719 & 0.343 & 0.375 & 0.336 & 0.161 \\
\hline
\end{tabular}


Table A.3 Goodness of fit and log-likelihoods

\begin{tabular}{|c|c|c|c|c|}
\hline & Commodity & Good Fit & Log like MS & Log like AR1 \\
\hline 1 & ALUMINUM & $*$ & 1324.05 & 1052.43 \\
\hline 2 & BEEF:AUSTRALIA & * & 1085.09 & 971.21 \\
\hline 3 & COCOA BEANS & * & 846.12 & 810.19 \\
\hline 4 & COCONUT OIL:PHILIPPINES & $*$ & 808.64 & 743.51 \\
\hline 5 & COFFEE:OTHER MILDS & & & \\
\hline 6 & COFFEE:BRAZIL (NEW YORK) & * & 917.59 & 704.98 \\
\hline 7 & COFFEE:UGANDA & * & 933.26 & 801.41 \\
\hline 8 & COPPER & * & 914.05 & 808.96 \\
\hline 9 & COPRA:PHILIPPINES & * & 788.28 & 697.84 \\
\hline 10 & COTTON:LIVERPOOL & & & \\
\hline 11 & FISHMEAL & * & 975.12 & 802.26 \\
\hline 12 & GROUNDNUTS:NIGERIA & & & \\
\hline 13 & GROUNDNUT OIL & * & 994.11 & 888.2 \\
\hline 14 & HIDES & & & \\
\hline 15 & IRON ORE:BRAZIL (US CENTS/DMTU) & * & 1658.8 & 979.55 \\
\hline 16 & JUTE:BANGLADESH & * & 1114.39 & 834.96 \\
\hline 17 & LAMB:NEW ZEALAND & * & 1029.71 & 976.75 \\
\hline 18 & LEAD & * & 924.03 & 825.94 \\
\hline 19 & LINSEED OIL & * & 913.65 & 787.38 \\
\hline 20 & MAIZE: US & * & 1046.49 & 984.09 \\
\hline 21 & NICKEL & * & 1236.08 & 825.63 \\
\hline 22 & PALM OIL:MALAYSIA & * & 856.08 & 753.84 \\
\hline 23 & PETROLEUM:AVERAGE CRUDE PRICE & * & 1149.59 & 742.43 \\
\hline 24 & PETROLEUM:DUBAI & & & \\
\hline 25 & PETROLEUM:UK BRENT & & & \\
\hline 26 & PHOSPHATE ROCK:MOROCCO & * & 1685.7 & 798.76 \\
\hline 27 & POTASH & * & 1476.11 & 521.27 \\
\hline 28 & RICE:THAILAND (BANGKOK) & & & \\
\hline 29 & RUBBER:MALAYSIA & & & \\
\hline 30 & SHRIMP: U.S. GULF & $*$ & 808.74 & 700.73 \\
\hline 31 & SISAL:EAST AFRICA & & & \\
\hline 32 & SOYBEANS: US & * & 1026.59 & 894.21 \\
\hline 33 & SOYBEAN MEAL & & & \\
\hline 34 & SOYBEAN OIL & $*$ & 884.6 & 845.38 \\
\hline 35 & SUGAR:EU & & & \\
\hline 36 & SUGAR:CARIBBEAN & & & \\
\hline 37 & SUGAR:US & * & 1284.04 & 904.44 \\
\hline 38 & TEA & * & 758.34 & 686.76 \\
\hline 39 & TIMBER:HARDWOOD LOGS:SARAWAK & & & \\
\hline 40 & TIN & & & \\
\hline 41 & WHEAT U.S. GULF & & & \\
\hline 42 & WOOL:AUSTRALIA:48:COARSE & * & 1065.21 & 1001.78 \\
\hline 43 & WOOL:AUSTRALIA:64:FINE & & & \\
\hline 44 & ZINC & * & 973.82 & 873.43 \\
\hline
\end{tabular}

* This test is if all Markov switching coefficient are statistically significant at a $10 \%$. The fourth and fifth column show the log likelihoods for the Markov switching and the AR1 processes, respectively. 
Figure A.1 Commodity Prices (constant US dollars)
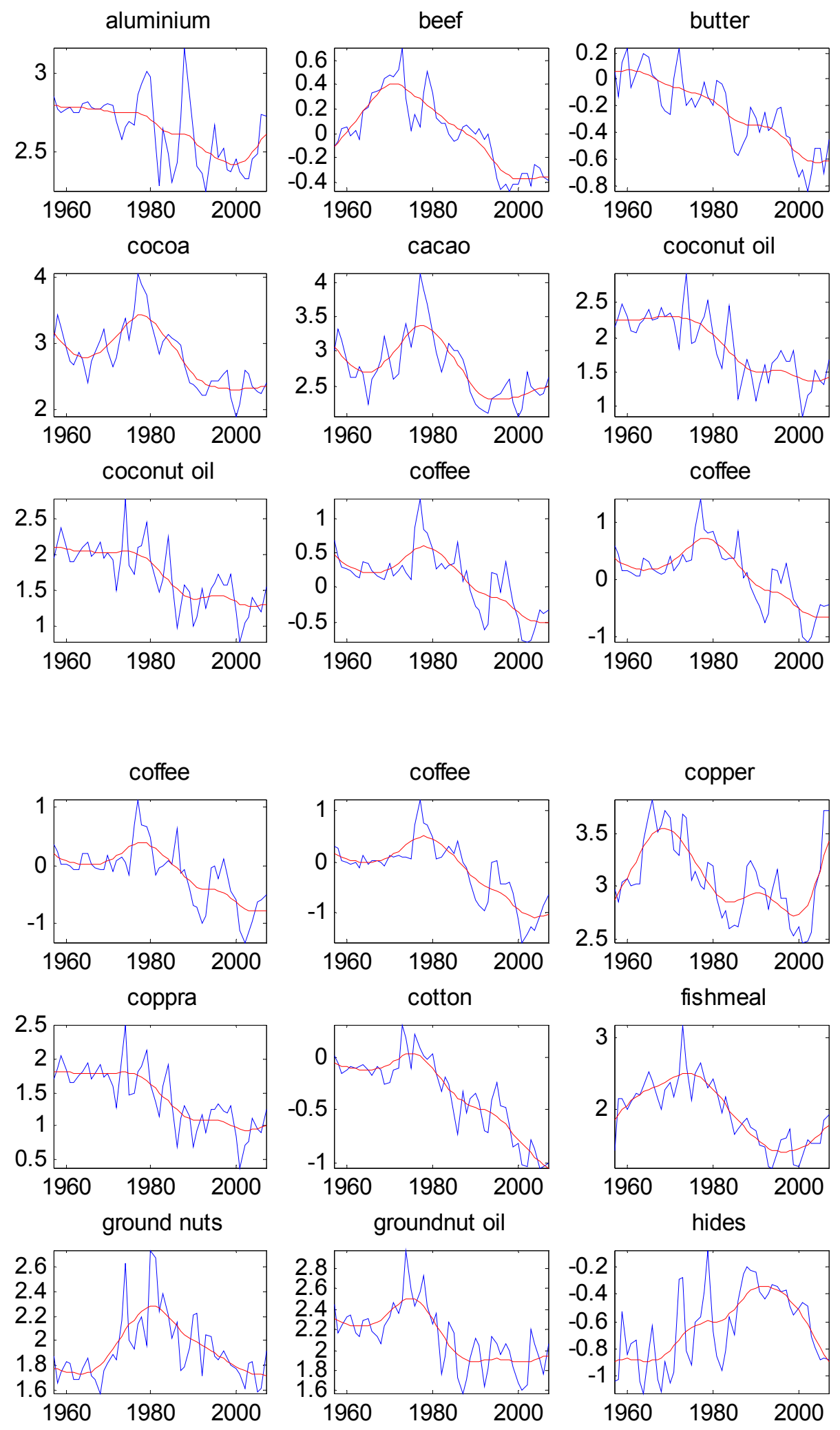

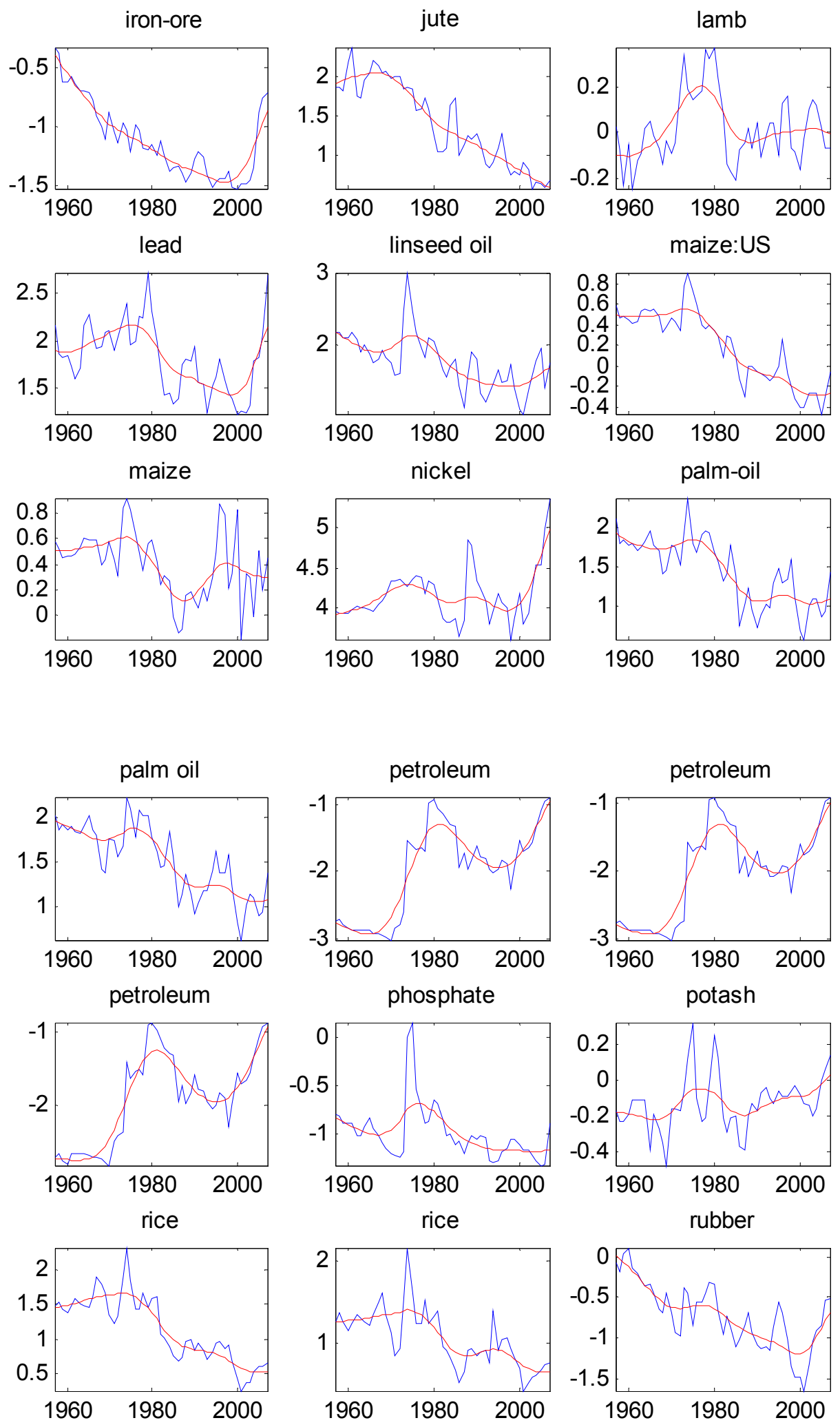

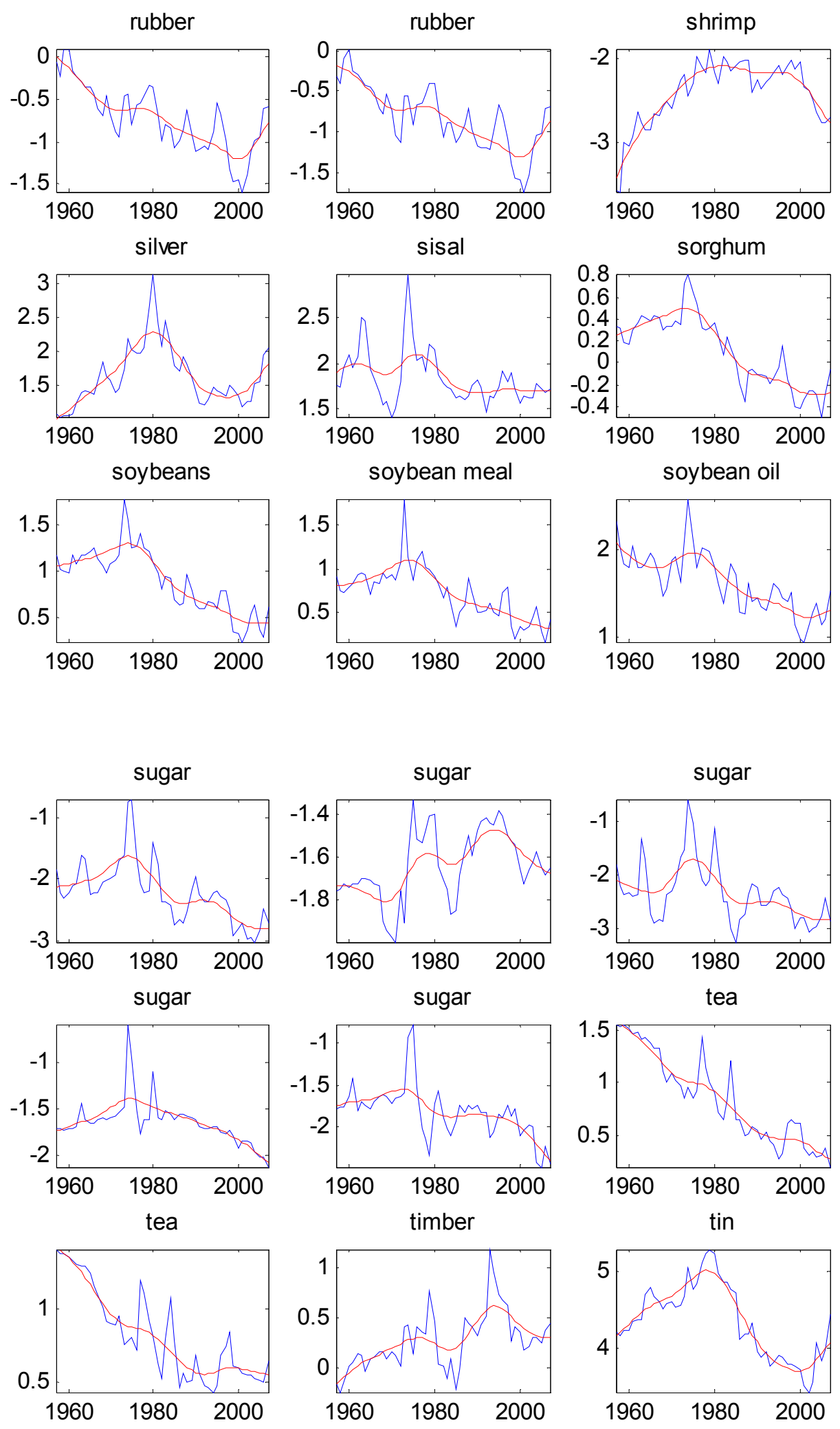

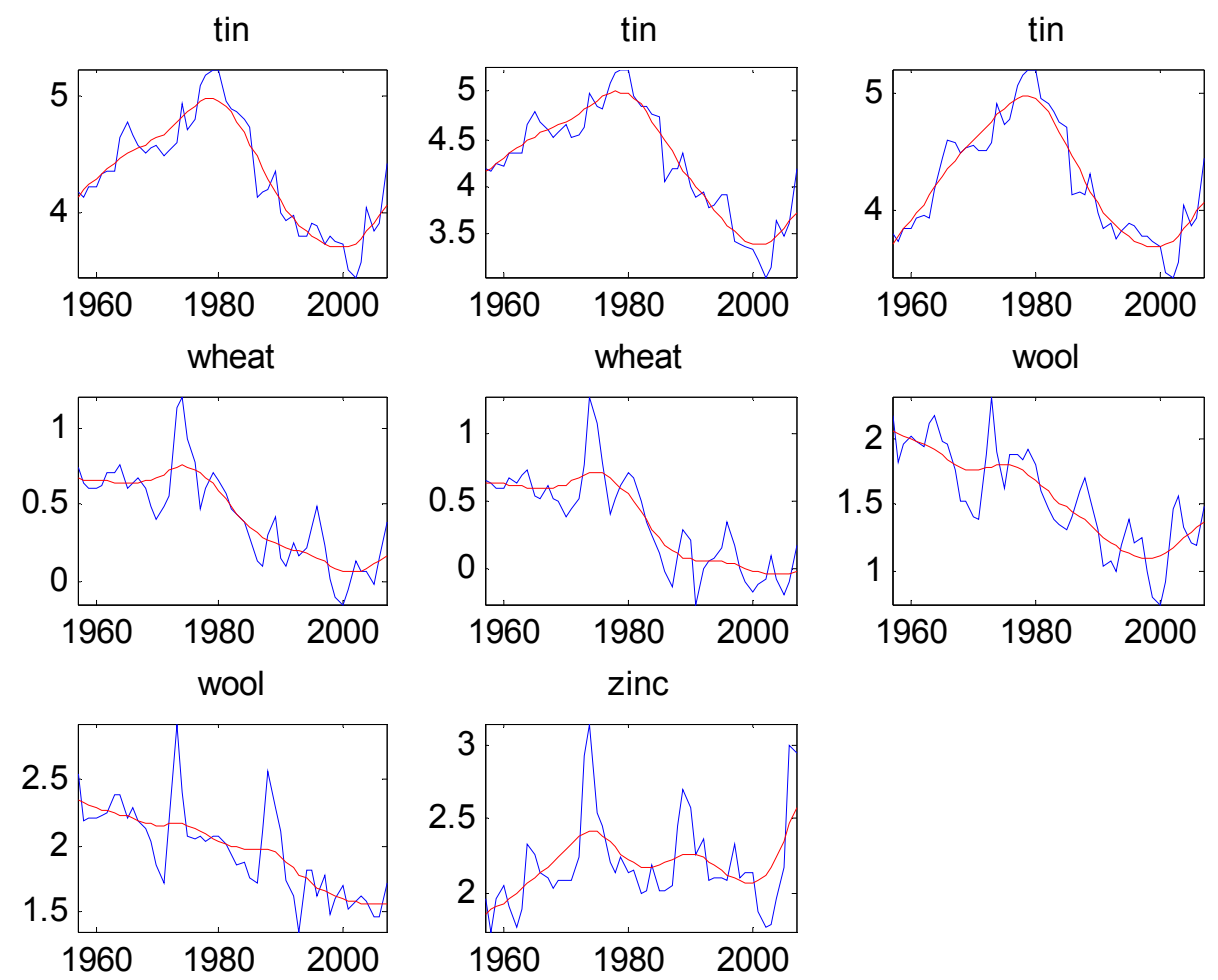
Figure A.2.1 Rolling-window means (15-years)
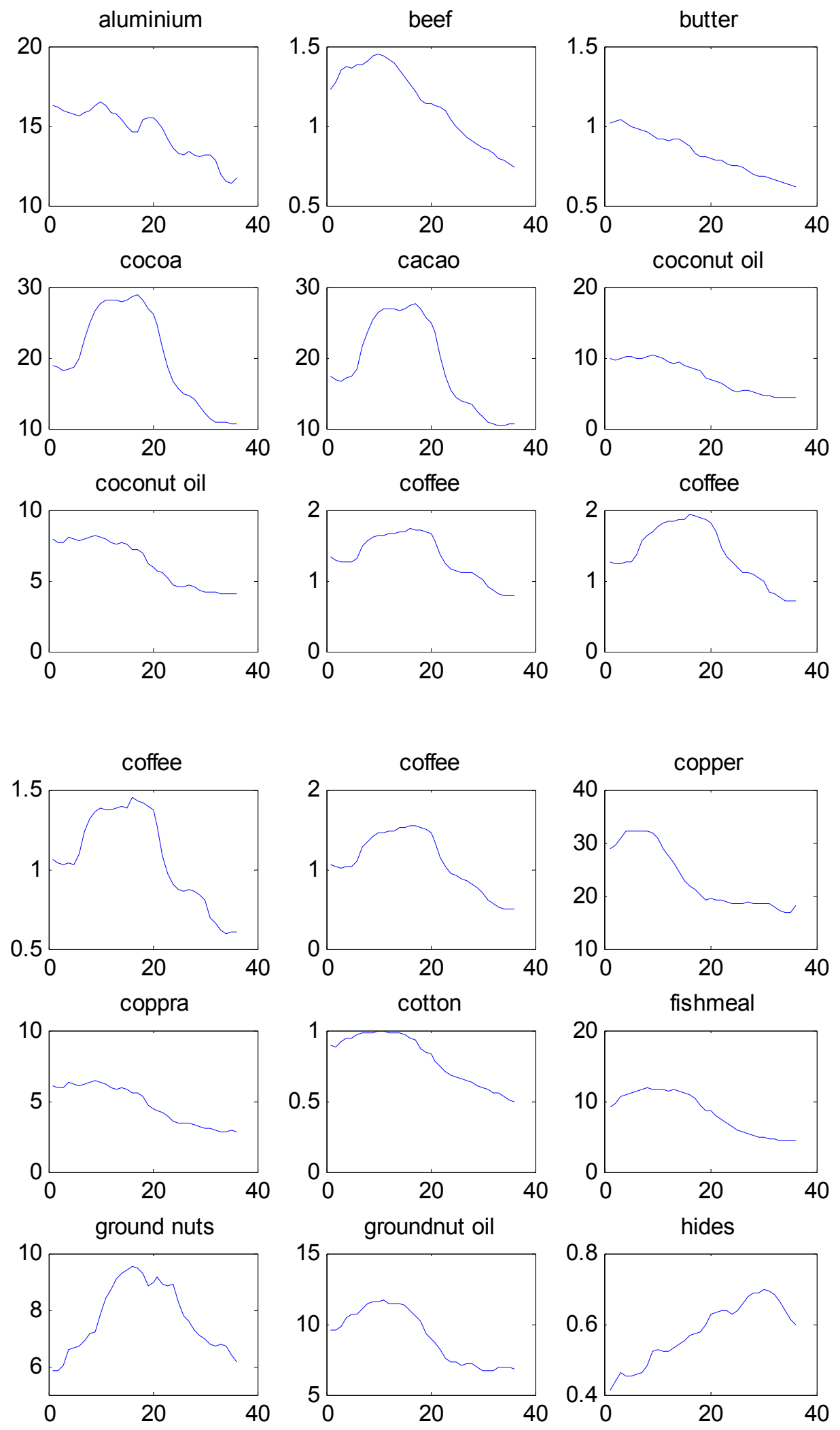

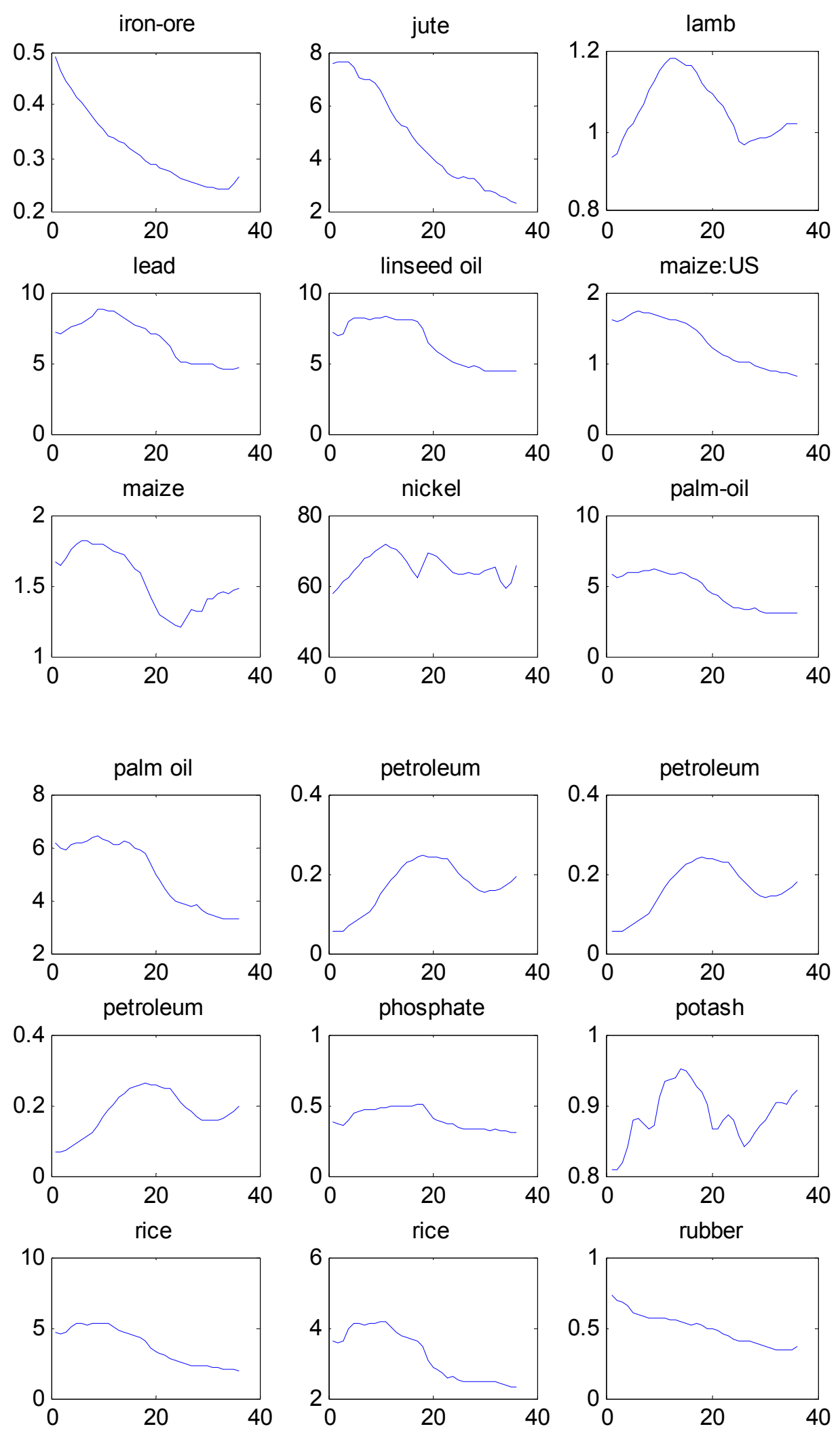

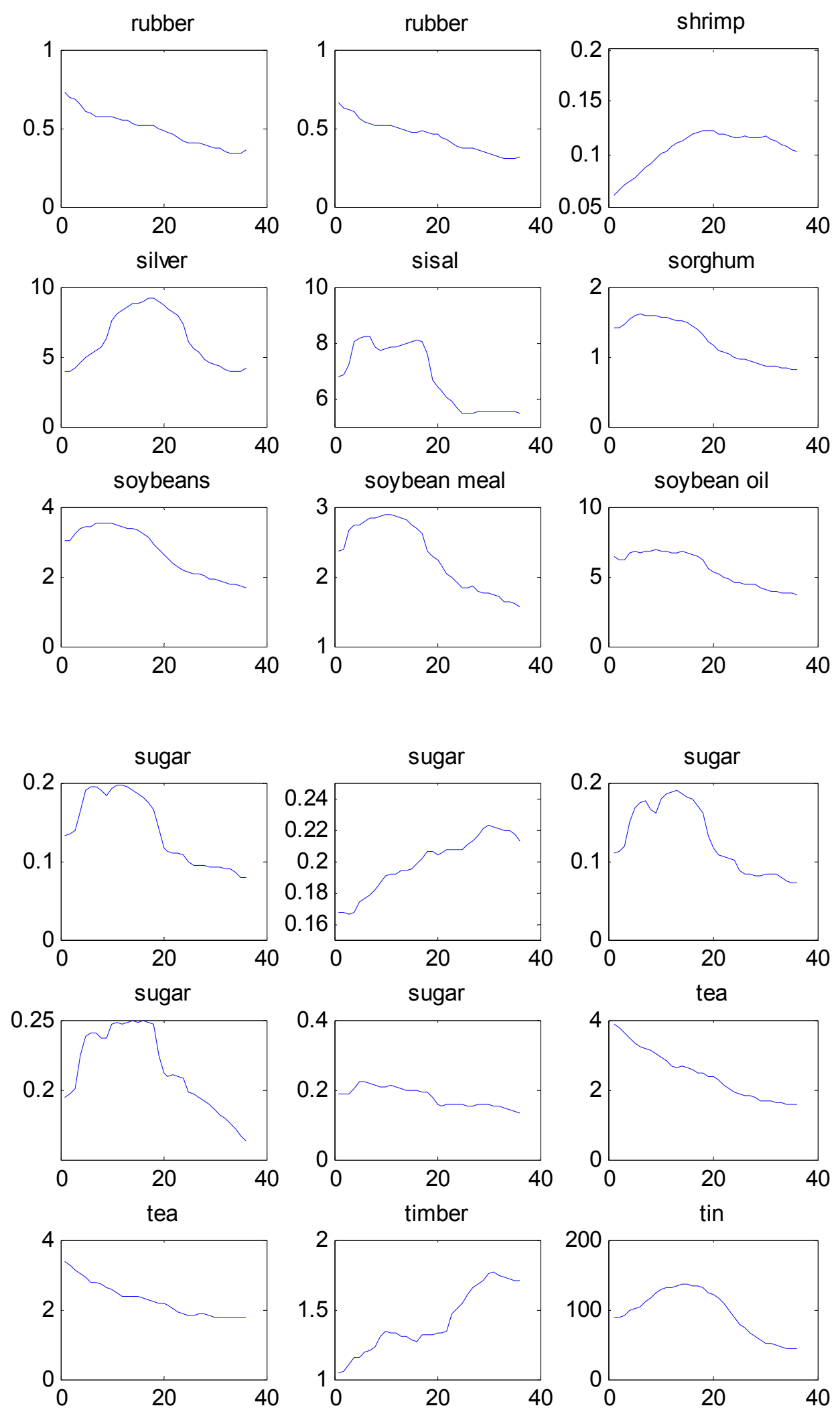

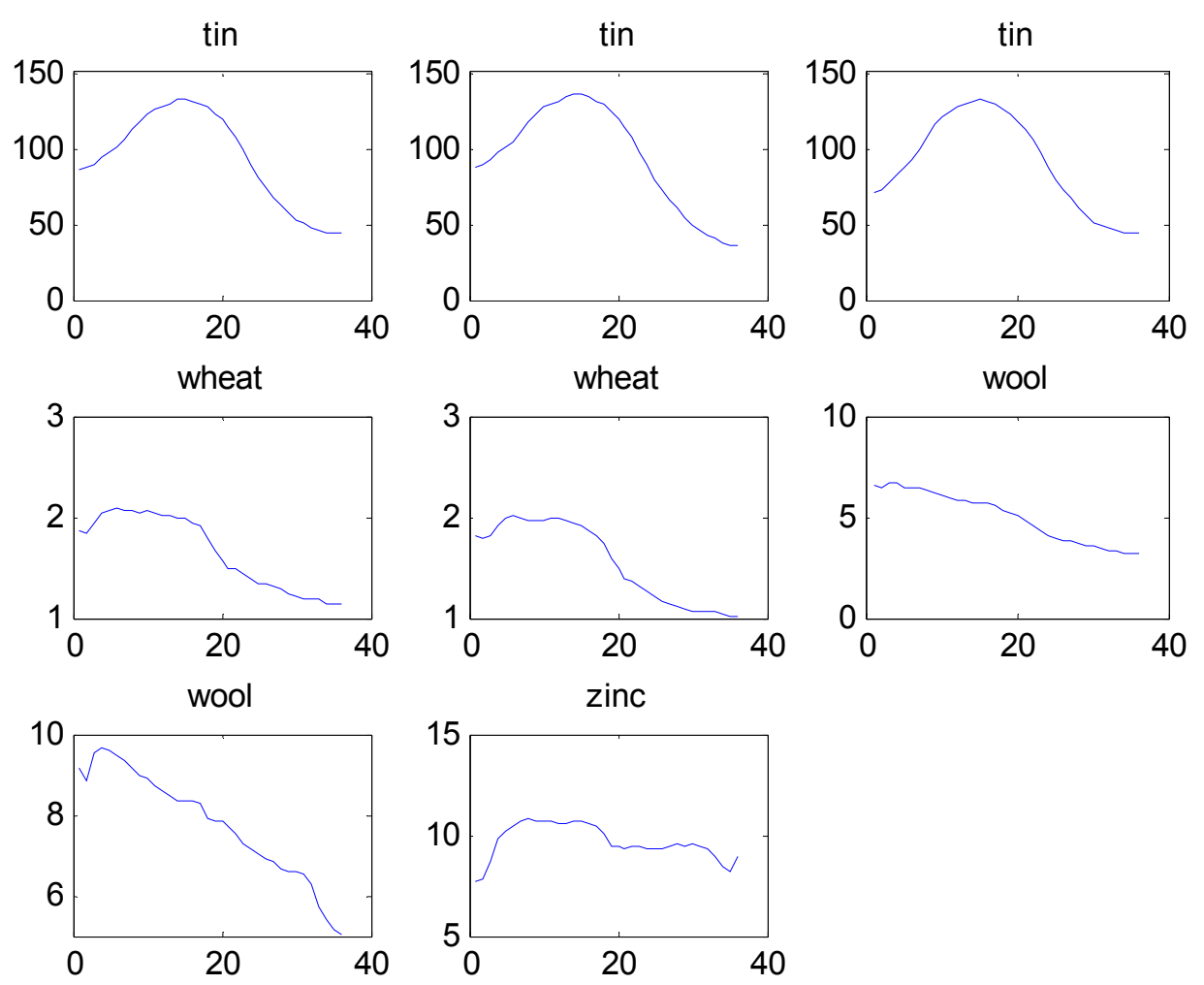
Figure A.2.2 Rolling-window coefficients of variation (15-years)
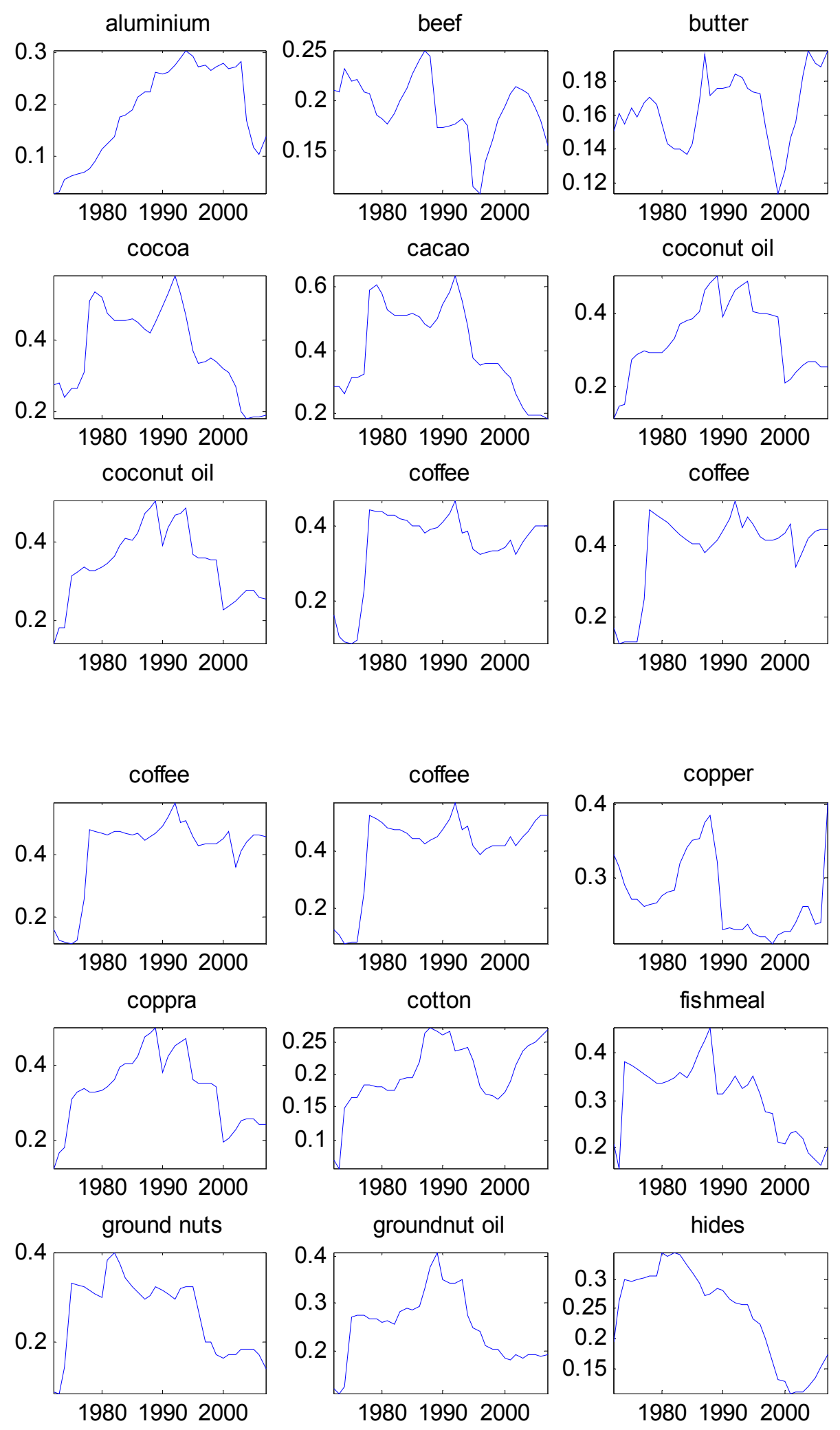

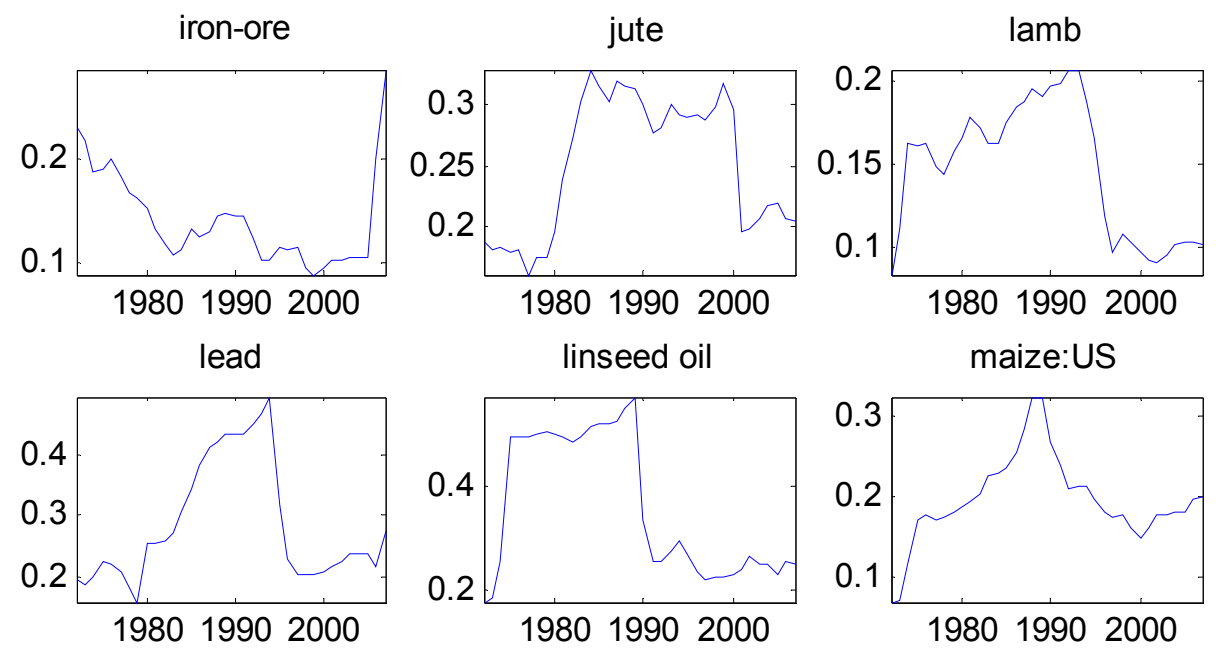

linseed oil

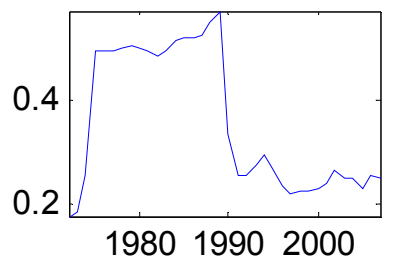

maize:US
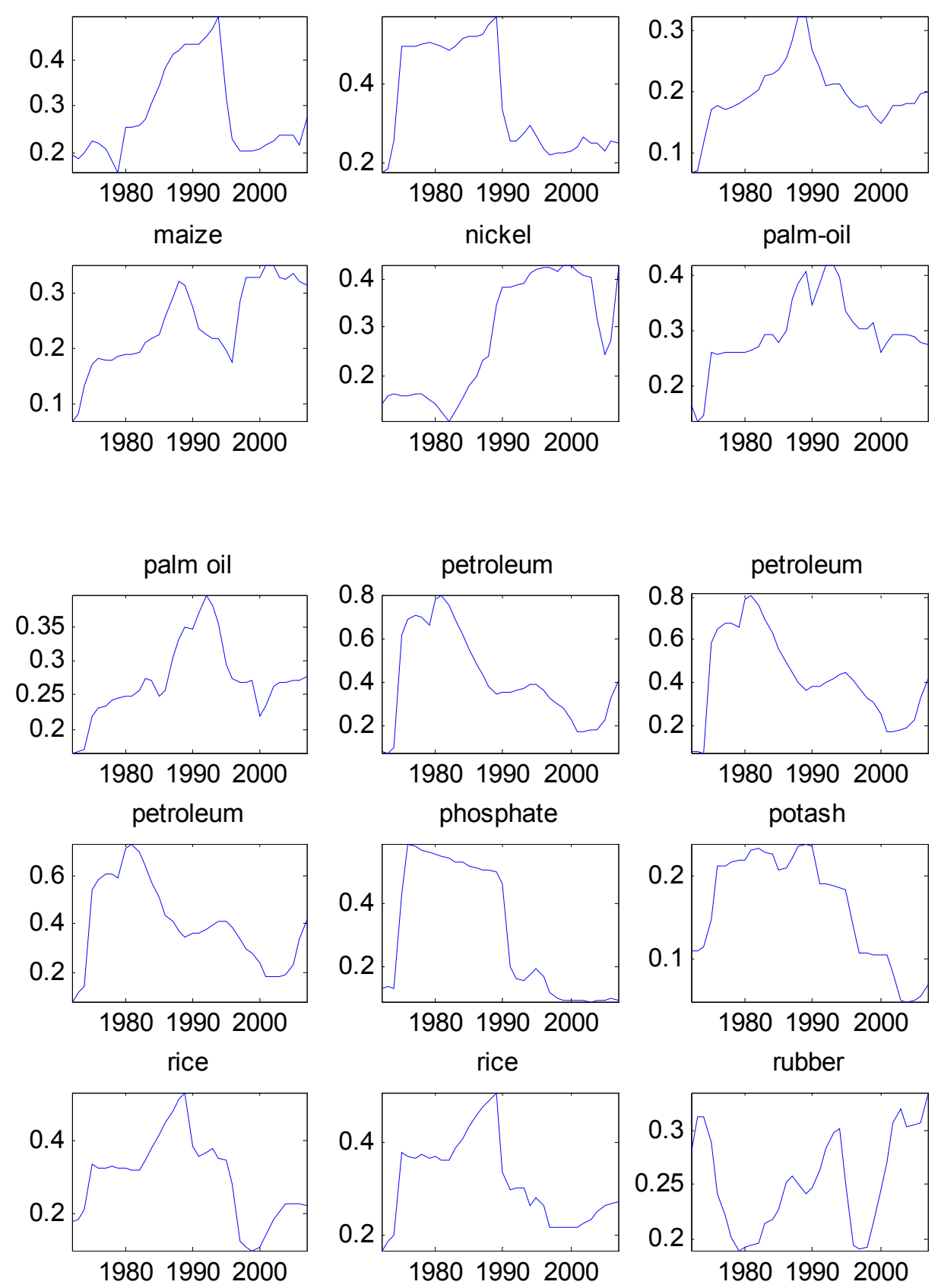

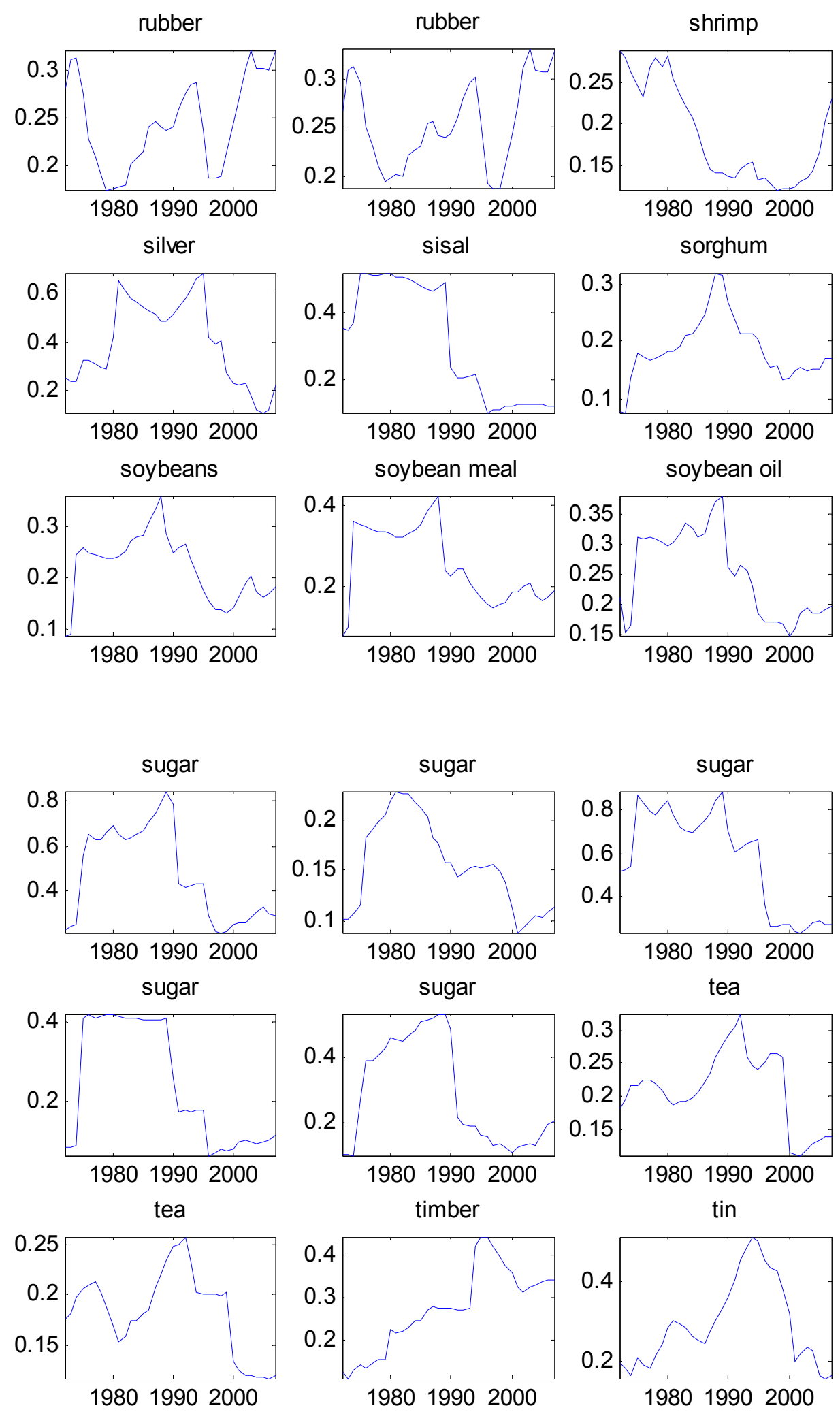

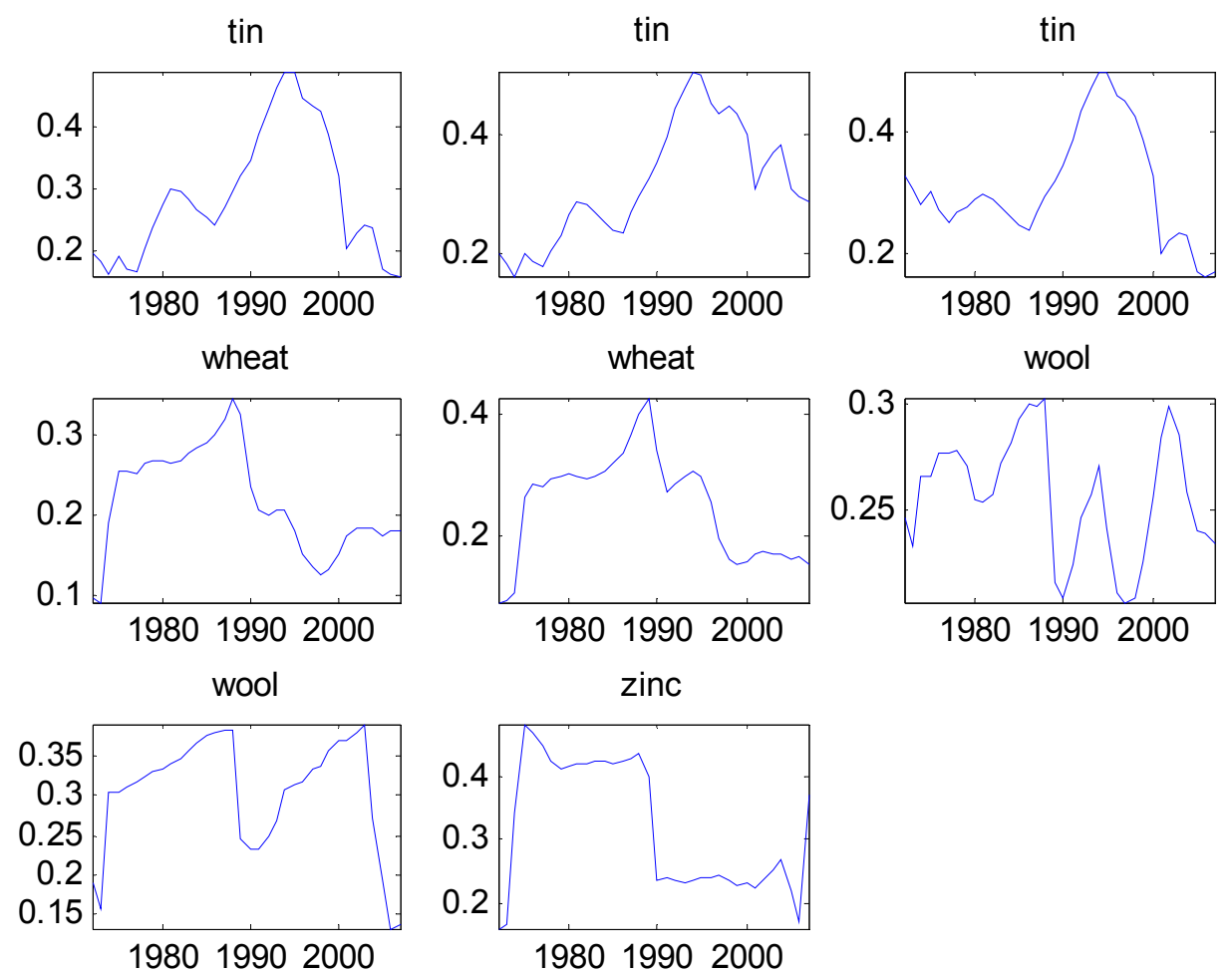
Figure A.2.3 Rolling-window autocorrelations (15-years)
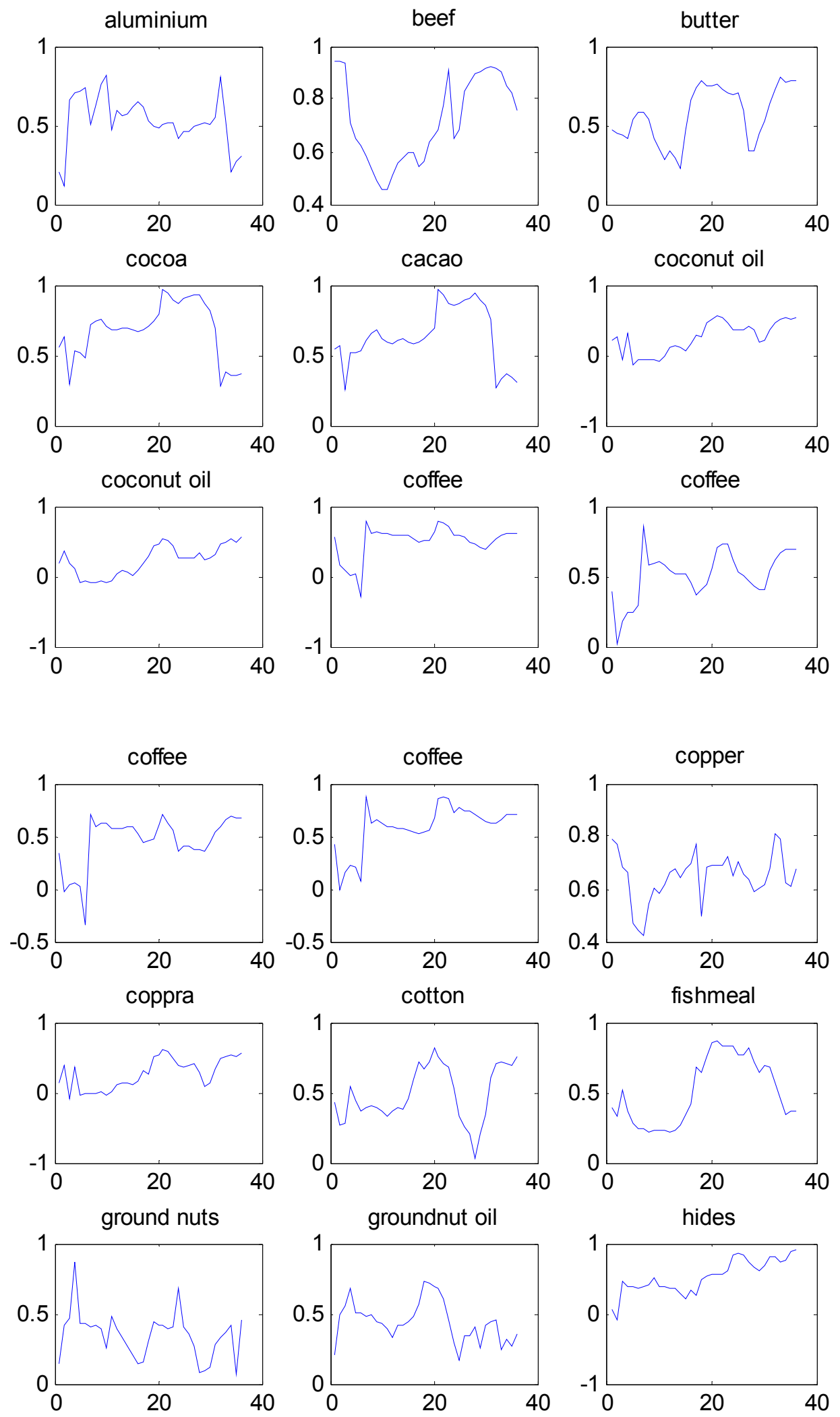

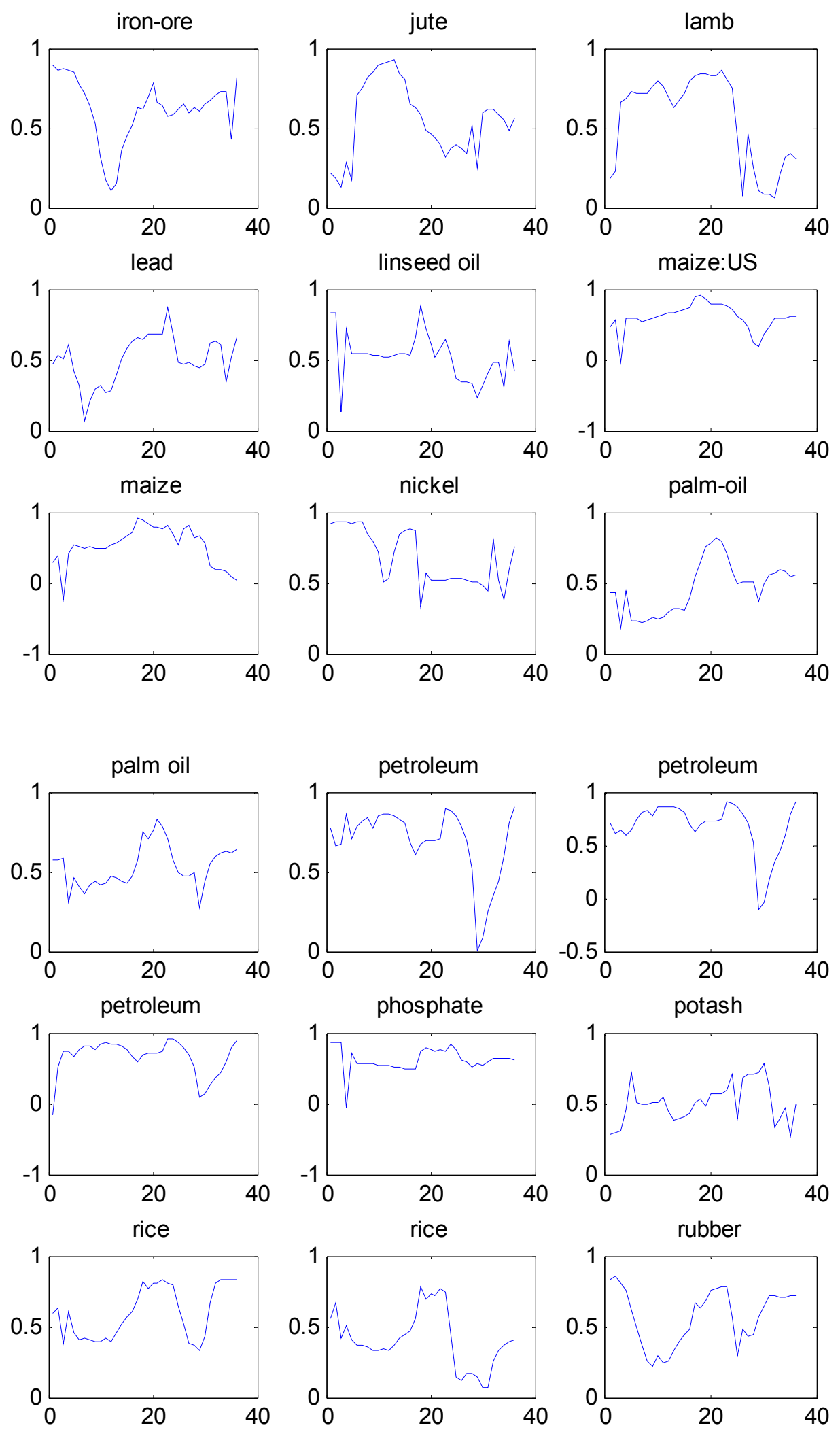

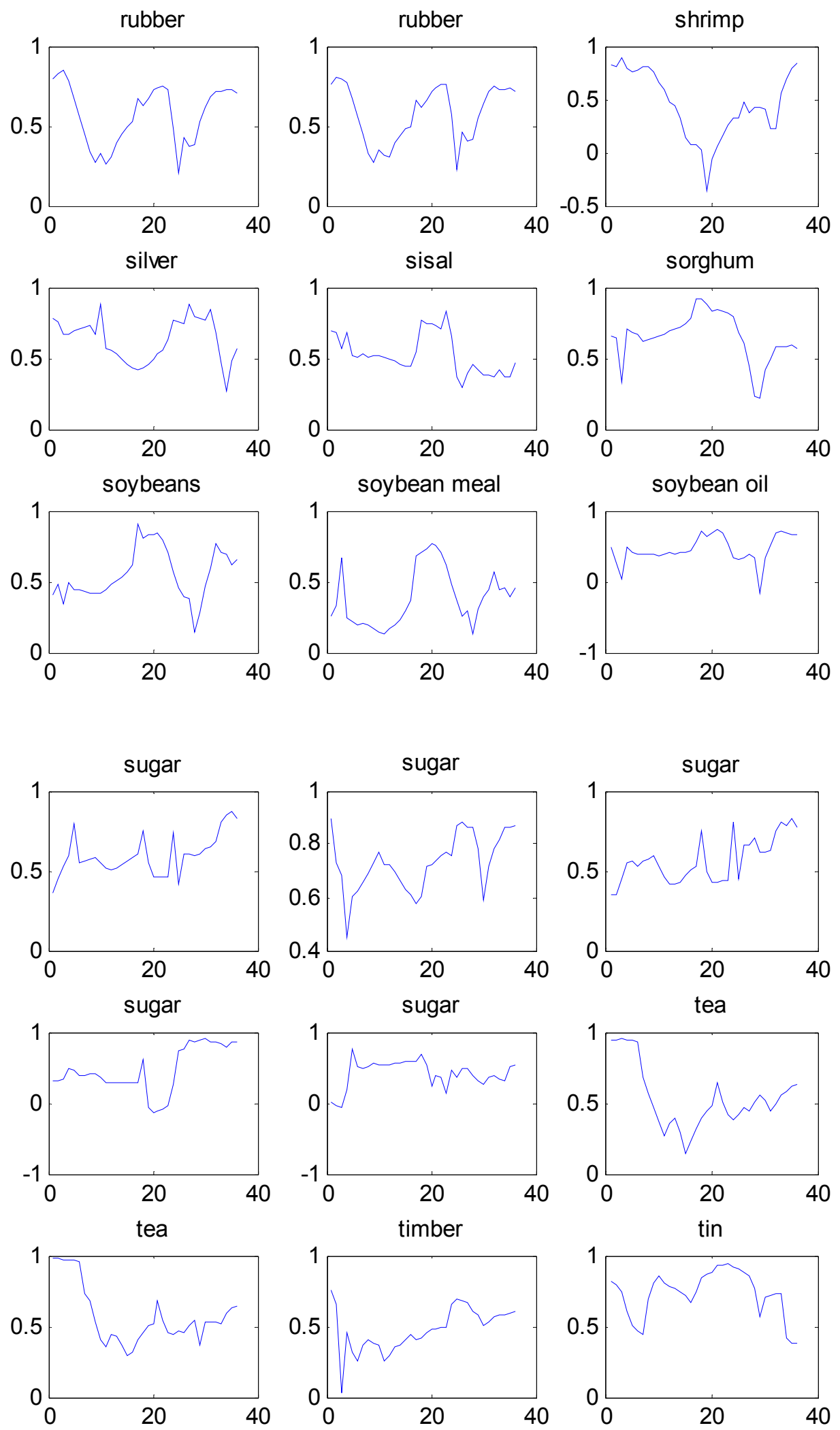

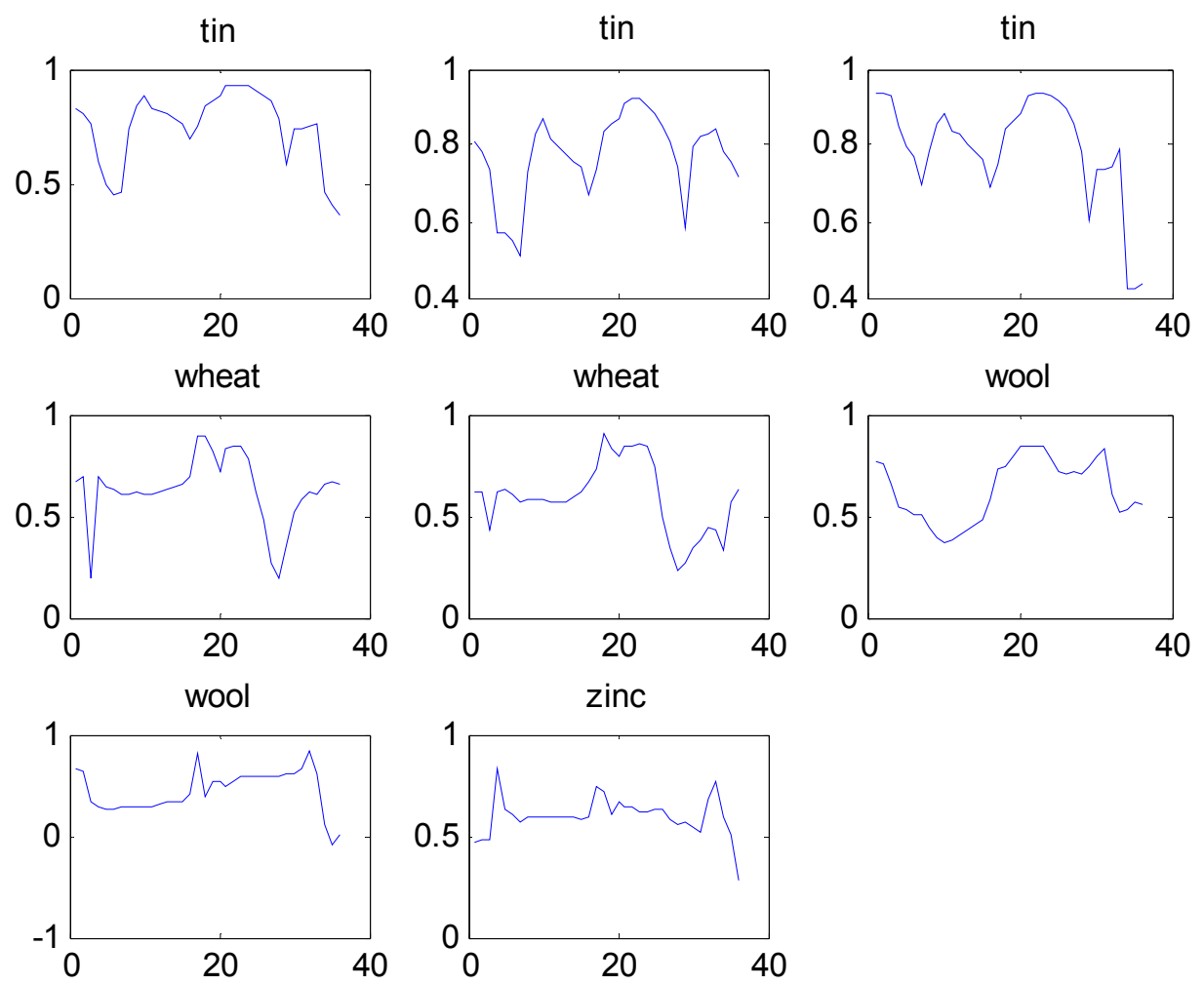


\section{REFERENCES}

Aghion, P., G.-M. Angeletos, A. Banerjee and K. Manova, 2010, "Volatility and growth: Credit constraints and the composition of investment," Journal of Monetary Economics, 57: 246-265.

Aguiar, M. and G. Gopinath, 2007, "Emerging Market Business Cycles: The Cycle is the Trend," Journal of Political Economy, 115(1): 69-102.

Boz, E., 2009, "Can Miracles Lead to Crises? The Role of Optimism in Emerging Market Crises," Journal of Money, Credit, and Banking 41(6): 1189-1215.

Boz, E., C. Daude, and C.B. Durdu, 2008, "Emerging Market Business Cycles Revisited: Learning about the Trend," International Finance Division Paper \#927, Board of Governors of the Federal Reserve System, Washington, DC.

Broda, C., 2004, "Terms of Trade and Exchange Rate Regimes in Developing Countries," Journal of International Economics, 63: 31-58.

Carroll, C. D., 2004, “Theoretical Foundations of Buffer Stock Saving," NBER Working Paper 10867, National Bureau of Economic Research, Cambridge, MA.

Cashin, P., H. Liang, and C. J. McDermott, 1999, "How Persistent Are Shocks to World Commodity Prices?” IMF Staff Papers, 47 (2): 117-217.

Cochrane, J. H., 1988, "How Big is the Random Walk in GNP?” Journal of Political Economy 96: 893-920.

Deaton, A. S., 1991, “Saving and Liquidity Constraints,” Econometrica, 59: 1221-1248.

Deaton, A. S., 1999, "Commodity Prices and Growth in Africa," Journal of Economic Perspectives, 13 (3): 23-40.

Deaton, A. S. and G. Laroque, 1992, “On the Behavior of Commodity Prices," Review of Economic Studies 59: 1-23.

Dreze, J. and F. Modigliani, 1972, "Consumption Decisions Under Uncertainty," Journal of Economic Theory 5: 308-335.

Engel, E. and R. Valdes, 2001, "Prediciendo el Precio del Cobre: Mas allá del Camino Aleatorio?", Documentos de Trabajo 100, Centro de Economía Aplicada, Universidad de Chile.

Ghosh, A., and J. Ostry, 1994, "Export Instability and the External Balance in Developing Countries," IMF Staff Papers 41(2): 214-235.

Grilli, E. R. and M. C. Yang, 1988, "Primary Commodity Prices, Manufactured Goods Prices, and the Terms of Trade of Developing Countries: What the Long Run Shows," World Bank Economic Review 2: 1-47. 
Hamilton, J. D., 1989, “A New Approach to the Economic Analysis of Nonstationary Time Series and the Business Cycle," Econometrica 57(2): 357-384.

Kimball, M. S., 1990, "Precautionary saving in the small and in the large," Econometrica 58: 53-73.

Kose, M. A., 2002, "Explaining business cycles in small open economies: How much do world prices matter?", Journal of International Economics 56: 299-327.

Leland, H., 1968, "Saving and Uncertainty: The Precautionary Demand for Saving," Quarterly Journal of Economics 82: 465-73.

Leon, J. and R. Soto, 1995, "Structural Breaks and Long-Run Trends in Commodity Prices," Journal of International Development 9: 347-366.

Mendoza, E.G., 1995, "The Terms of Trade, the Real Exchange Rate, and Economic Fluctuations," International Economic Review 36: 101-137.

Mendoza, E.G., 1997, “Terms-of-trade uncertainty and economic growth,” Journal of Development Economics 54: 323-356.

Obstfeld, M. and K. Rogoff, 1996. Foundations of International Macroeconomics, MIT Press, Cambridge, MA.

Ramey, G. and V. Ramey, 1995, "Cross-country Evidence on the Link between Volatility and Growth," American Economic Review 85: 1138-1151.

Ravn, M. O. and H. Uhlig, 2002, "On adjusting the Hodrick-Prescott filter for the frequency of observations," Review of Economics and Statistics 84(2): 371-375.

Reinhart, C. and P. Wickham, 1994, "Commodity Prices: Cyclical Weakness or Secular Decline?” IMF Staff Papers 41: 175-213.

Roitman, A., 2010, "Precautionary Savings in a Small Open Economy Revisited". Mimeo. University of Maryland. Unpublished.

Sandmo, A., 1970, "The Effects of Uncertainty on Saving Decisions," Review of Economic Studies 37: 353-360.

Skinner, J., 1988, "Risky Income, Life Cycle Consumption and Precautionary Saving," Journal of Monetary Economics 22: 237-55.

Van Nieuwerburgh, S. and L. Veldkamp, 2006, "Learning asymmetries in real business cycles," Journal of Monetary Economics 53(4): 753-772,

Zeldes, S., 1989, “Optimal Consumption with Stochastic Income: Deviations from Certainty Equivalence” Quarterly Journal of Economics 104: 275-298. 